\title{
Extreme smog challenge of India intensified by increasing lower tropospheric stability
}

Ritesh Gautam ${ }^{1 * \dagger}$, Piyushkumar N. Patel ${ }^{2,3 \dagger}$, Manoj K. Singh ${ }^{4}$, Tianjia Liu ${ }^{5}$, Loretta J. Mickley ${ }^{6}$, Hiren Jethva ${ }^{3,7}$, Ruth S. DeFries ${ }^{8}$

${ }^{1}$ Environmental Defense Fund, Washington DC, USA.

${ }^{2}$ NASA Jet Propulsion Laboratory, Pasadena, CA, USA.

${ }^{3}$ Universities Space Research Association, Columbia, MD, USA.

${ }^{4}$ School of Engineering, University of Petroleum and Energy Studies, Dehradun, India.

${ }^{5}$ Department of Earth and Planetary Sciences, Harvard University, Cambridge, MA, USA.

${ }^{6}$ School of Engineering and Applied Sciences, Harvard University, Cambridge, MA, USA.

${ }^{7}$ NASA Goddard Space Flight Center, Greenbelt, MD, USA.

${ }^{8}$ Department of Ecology, Evolution, and Environmental Biology, Columbia University, New York, NY, USA.

*Correspondence to: rgautam@edf.org

†These authors contributed equally to this work.

Author Contributions: R.G. designed the study. P.N.P. and R.G. carried out the data analysis and interpretation with contributions from M.K.S. All authors discussed the results. R.G. wrote the manuscript. P.N.P., M.K.S., T.L., L.J.M., H.J. and R.D.S. reviewed, commented and/or edited the manuscript.

Competing Interest Statement: Authors declare that they have no competing interests.

Keywords: Smog, India, Aerosols, Satellite remote sensing 


\section{Abstract}

Air pollution in India severely impacts the air quality, public health and economy in one of the world's most densely populated regions. Persistent agricultural fires during the late-autumn period and widespread winter-time pollution contribute to the extreme smog in south Asia, especially affecting the entire northern India. While the links between anthropogenic emissions, air quality and health impacts have been well recognized, the association of smog and its intensification with climatic trends in the lower troposphere, where aerosol pollution and its radiative effects manifest, are not understood well. Here we use long-term satellite data to show a significant increase in aerosol exceedances over northern India, resulting in sustained aerosol-induced atmospheric warming and surface cooling trends over the last two decades. We further find several lines of evidence that these aerosol radiative effects may have amplified a multidecadal (1980-2019) strengthening of lower tropospheric stability along with an increase in relative humidity, in turn intensifying the smog and leading to more than fivefold increase in poor visibility days. Given this crucial aerosol-radiation-meteorological feedback, we anticipate results from this study will help inform mitigation strategies supporting stronger region-wide measures, which are critical for solving the smog challenge in India.

\section{Significance statement}

Severe air pollution in India and its impacts on air quality and public health are worsening. Extreme smog episodes are frequently observed in northern India associated with the highest aerosol concentrations and hazardous visibility conditions. It is well-known that anthropogenic emissions directly affect pollution, but it remains unclear from an observational perspective how the stability of the lower troposphere, where aerosol pollution builds up, impacts the long-term evolution of smog. Using a multidecadal analysis of satellite, ground and reanalysis datasets, here we show sustained intensification of extreme smog associated with the strengthening of lower tropospheric stability, potentially amplified by aerosol-induced atmospheric warming. Solving the smog crisis in India is increasingly critical given the strongly linked aerosolradiation-meteorological interactions.

\section{Main Text}

\section{Introduction}

Air pollution in India severely impacts air quality, public health and economy in one of the world's most densely populated regions (1-5). Persistent agricultural fires during late autumn period (612) and widespread winter-time pollution (13-19) contribute to the extreme smog over south Asia, especially affecting entire northern India. The late autumn and winter months are the worst smog periods, resulting in the largest degradation of air quality in the Indo-Gangetic Plains (IGP), where nearly one-seventh of the world's population lives across northern India, Pakistan, Nepal and Bangladesh. In recent years, northern India has witnessed some of the most intense smog spells with extremely low visibility and hazardous air quality. The persistent smog invariably attracts heightened public and media attention (20) owing to the anomalous levels of fine particulate matter $\left(\mathrm{PM}_{2.5}\right)$ recorded between November and January, every year. For instance, daily $\mathrm{PM}_{2.5}$ concentrations during agricultural burning, frequently exceed $200 \mu \mathrm{g} / \mathrm{m}^{3}$, an order of magnitude larger than the World Health Organization's air quality guideline $(9-11,20)$. In addition to health 
and economic impacts of pollution (1-5), impacts of smog include prolonged delays/cancellations of trains and flights, and even vehicular accidents in northern India $(13,15,21)$.

While the worsening air quality in India has deservedly received growing attention, the linkages between smog intensification and climatic trends in the lower troposphere where aerosol pollution occurs, are not understood well. On the other hand, it is well known that sunlight-absorbing aerosols lead to atmospheric warming and surface cooling via aerosol radiative effects (22), thereby increasing the stability of the lower troposphere by inducing a temperature inversion $(23,24)$. A stable lower troposphere implies reduced dispersion of pollutants leading to further accumulation of aerosols in the shallow boundary layer. Here, from an observational perspective, we examine lower-tropospheric changes during the last 40 years to investigate such aerosolradiation-meteorological feedbacks for gaining new insights into the extreme smog problem in northern India and unraveling its long-term intensification.

\section{Results}

We start with characterizing aerosol trends in northern India, where much of the agricultural burning occurs in the northwestern state of Punjab, the so-called breadbasket of the country and among the largest producing rice and wheat crop states nationally. Figure 1 shows the long-term climatology of satellite-derived aerosol optical depth (AOD), an indicator of aerosol loading, over south Asia averaged during the last two decades from MODIS observations (see datasets description in SI Appendix). The spatial distribution of AOD indicates pronounced enhancement in the IGP, along the southern edge of the Himalaya. November is the dominant crop burning month in recent years when peak fire activity and subsequent aerosol loading has increased $(8,11)$ and is separately shown from December-January mean (winter haze period) (Fig. 1). We find accelerated upward trends in November AOD, which are higher by a factor of $>3$ relative to the annual-mean trend over northern India (Fig. S1), leading to a $~ 90 \%$ increase in November from 2002 to 2019 (Fig. 2A).

In order to characterize changes in extreme smog, we report AOD exceedances (see Datasets section in SI Appendix) indicating an even larger increase of $~ 140 \%$ in November over northern India (Fig. 2B). This upsurge appears consistent with increase in agricultural fire activity, attributed to a government-mandated delay in transplanting of rice seedlings (contributing to increased burning in a shorter timespan) and expanded crop productivity in Punjab (8-11). With respect to the winter months, northern India experiences the largest aerosol loading (AOD > 0.8) over central-eastern IGP (Fig. 1C), where population density is the highest across states of eastern Uttar Pradesh, Bihar and West Bengal. The winter smog is known to be associated with a shallow boundary layer, frequent temperature inversion, light winds and high relative humidity (13-19). Similar to November, although smaller in magnitude, we find significant positive trends in winter AOD (Fig. 1D and Fig. 2A), which are $>1.5$ times higher than the annually-averaged trend (Fig. $\mathrm{S} 1$ ). There is a $>40 \%$ rise in winter aerosol exceedances during the last two decades (Fig. 2B), with the largest increase of $\sim 60 \%$ in central-eastern IGP (Fig. 1D). We also find upward trends in ground-based and other satellite datasets (Fig. S2, S3, S4), during both crop burning and winter haze, supporting the observation of intensification of aerosol pollution as detected in multiple disparate measurements.

How does the increased aerosol pollution impact the regional radiation budget? We analyze the direct radiative effect of aerosols, specifically to characterize the impact of increasing AOD on 
surface cooling and atmospheric warming trends using solar radiation fluxes from CERES satellite observations (see Methods and SI Appendix Datasets sections). A consistent increase is found in top-of-atmosphere (TOA) flux (Fig. S5) and a reduction in surface-reaching radiation (implying surface cooling), corresponding to cloud-free aerosol-laden observations during the last two decades (Fig. 2C). An example of the relationship between collocated AOD and radiation fluxes (Fig. S6), indicates a positive aerosol-induced effect at the TOA (brightening) and negative effect at surface (cooling). The surface cooling associated with crop burning and winter haze is evident across the IGP, leading to over 15-25\% instantaneous reduction in solar insolation (Fig. S6, S7).

Our central finding in the radiative effects analysis is the net increase in aerosol-induced surface cooling, from 2002 to 2019, is twice as large compared to the increase in TOA flux. This disparity implies that considerably less radiation is being reflected at TOA as a result of significant solar absorption within the aerosol layer, in turn causing the large surface cooling anomaly. This is consistent with the low aerosol single scattering albedo in northern India $(25,26)$, indicative of an absorbing aerosol layer. The resulting aerosol-induced absorption (Fig. 2D) and atmospheric heating rate (Fig. S8) is largely confined to the lowest $\sim 1.5 \mathrm{~km}$ of the troposphere, where most of the aerosol layer resides during late autumn-winter in northern India, as indicated by spaceborne lidar observations (Fig. S9). Overall, concurrent with enhanced surface cooling, there is a 70-80\% increase in aerosol-induced lower tropospheric warming over the last two decades (Fig. 2C, 2D), suggesting an increasing tendency toward a stable lower troposphere, which favors buildup of aerosol pollution in the shallow boundary layer where emissions from agricultural fires and other anthropogenic sources occur.

With aerosol-induced radiative effects evident in lower tropospheric warming and surface cooling, we then investigate whether long-term changes in atmospheric stability and related meteorological parameters have occurred in turn amplifying the smog intensification. Fig. 3 shows the climatology and trends of lower tropospheric stability (LTS) (27), a measure of the strength of temperature inversion that caps the planetary boundary layer (see SI Appendix Datasets section). The IGP emerges under a strong LTS influence during late autumn and winter, based on the past four decades of meteorological data (Fig. 3a and Fig. S10). The enhanced LTS is particularly evident over northern India, as part of an overall stable lower-tropospheric feature. We find a significant and sustained upward trend leading to an 18-25\% increase in LTS over northern India from 1980 to 2019 (Fig. 3B).

Coincidentally, the number of poor visibility days (defined here as visibility $<1000 \mathrm{~m}$ ) has increased fivefold over northern India during November and >2 times during December-January over the last 40 years (Fig. S11). This worsening trend is even severe for days with much lower visibility $(<500 \mathrm{~m})$, indicating a factor of $>9$ increase during the crop burning period and a fivefold increase in winter. Over Delhi, where pollution levels are among the highest in the world, the smog has undergone significant intensification (at least a fivefold increase for visibility $<500 \mathrm{~m}$ ), with poor visibility largely dominating the late autumn-winter periods since the 1990s (Fig. 3C, 3D). The degrading visibility is accompanied by a systematic $20 \%$ increase in near-surface relative humidity $(\mathrm{RH})$, over the last four decades, with high $\mathrm{RH}(85 \%-95 \%)$ observed in recent years (Fig. 3E). The association between RH and poor visibility indicates a higher correlation $(r$ : 0.770.85 , $p$-value $<<0.01$ ) for days with visibility $<500 \mathrm{~m}$ in both November and December-January 
months (Fig. 4A), relative to visibility < $1000 \mathrm{~m}$, supporting the observation of enhanced visibility degradation under humid conditions.

Overall, there appears to be an aerosol-radiation-meteorological feedback mechanism playing a potentially crucial role towards smog intensification whereby aerosol-induced atmospheric warming may strengthen the stability of the lower troposphere. This association is elucidated in Fig. 4B where aerosol-induced atmospheric warming is shown as a function of aerosol optical depth derived from co-located CERES and MODIS satellite observations, respectively; whereas the corresponding changes in LTS also co-located with aerosol-induced warming are indicated by the shading of the hexagon symbols. Based on daily observations aggregated from 19 years (20022019), we find that as the aerosol loading increases by a factor of 10 (from AOD $=0.1$ to AOD = 1.0), averaged over the IGP during the crop burning and winter haze periods, the aerosol-induced warming increases by $\sim 170 \%$, whereas the corresponding LTS also systematically increases by $\sim 50 \%$. At the same time, the co-located planetary boundary layer (PBL) over the IGP becomes systematically shallower by $\sim 30 \%$ (indicated by the size of the colored symbols), overlapping with simultaneous increases in AOD, aerosol-induced atmospheric warming and stability of the lower troposphere (Fig. 4B).

Altogether, as the aerosol-induced warming increases, the stability of the lower troposphere is found to significantly strengthen along with the deepening of PBL (as indicated by lower PBL heights at high AOD and vice versa). These distinct concomitant associations may not necessarily be construed as a cause-and-effect relationship, but they reveal observational insights related to aerosol-radiation-meteorological feedbacks, based on disparate variables and datasets, which favor the long-term intensification of smog. Increased stability means capping of pollutants and further increase in aerosol loading in the shallow PBL; at the same time entrainment of dry air from the free troposphere decreases, causing enhanced moisture availability in the PBL and higher RH $(18,23)$. The increase in $\mathrm{RH}$ enhances aerosol scattering mediated by the hygroscopic growth of aerosols, and promotes formation of secondary aerosols, further exacerbating the severity of smog $(14,24)$. We also find indication of the contraction of PBL in recent decades (see Fig. S12 and Methods), suggesting a moistened shallow boundary layer favorable for persistence of smoggy conditions.

The increase in RH may also in part be linked to the increase in irrigated area in the IGP; irrigation in India has expanded 2-3 times since the 1970s and may contribute to the enhanced moisture in the PBL (28). Regardless of the cause, smog intensification appears to be amplified by aerosolradiation-meteorological feedbacks, as observed in the increasing trends of aerosol-induced atmospheric warming and surface cooling, along with the long-term strengthening of lower tropospheric stability and concurrent trends in $\mathrm{RH}$ and visibility degradation during the last 40 years.

\section{Discussion}

It is noteworthy that extreme smog episodes in November, coinciding with agricultural burning, arrive in advance of the peak winter smog season in the IGP. As an illustration of the aerosolradiation-meteorological coupling, Fig. 4D shows the evolution of a dense smog spell in satellite imagery with thick haze around the beginning of November 2017, transforming into foggy conditions that altogether persisted for almost three weeks. The smog was so severe across 
northern India that the peak $\mathrm{PM}_{2.5}$ concentrations reached $\sim 1,000 \mu \mathrm{g} / \mathrm{m}^{3}$ in Delhi, prompting the closure of 4,000 schools (6) and a major international airliner to suspend its flight operations into the city (29). In another recent smog-filled episode, an international cricket match (most popular sport in south Asia) was halted probably for the first time in the sports' history due to smog, with players visibly sick and wearing pollution masks on the field (30). This intense degradation in air quality and visibility could have been amplified by a pronounced temperature inversion and high relative humidity in the lower troposphere (Fig. S13). We also analyzed 40 years of radiosonde observations of daily temperature profiles and found a twofold increase in the frequency of lower tropospheric temperature inversion (Fig. 4C), consistent with upward trends in LTS, visibility degradation and RH (Fig. 3).

Such extreme events serve as examples of the heightened attention the smog problem has increasingly received. On the other hand, there seems to be a lack of clarity regarding sources and transport mechanisms across states and countries in south Asia (31,32), which could be limiting effective measures to curb the pollution. In addition, connections of large-scale climatic patterns and interannual variability of aerosol pollution (17) may further add to the complexity of characterizing smog and its long-term intensification. Furthermore, the possible role of climate variability in contributing to poor ventilation conditions, suggested as conducive for extreme haze formation in China (33), may be worth investigating for studying severe pollution episodes in India. Such an analysis would benefit from large-scale climate model simulations involving landatmosphere-cryosphere interactions (33), beyond the observational findings this study has provided based on the synthesis of long-term satellite, surface and reanalysis datasets covering the past four decades.

The government of India, in October 2020, promulgated a major commission on air quality management in the national capital region (NCR) around Delhi and adjoining areas (34). This initiative distinctly recognizes the air pollution challenge in NCR; where adjoining areas are defined as "where any source of pollution is located causing adverse impact of air quality in the NCR" (34). As our results indicate, the increasing aerosol pollution and radiative impacts, clearly extend beyond NCR (<60 million population) and encompass the whole of northern India, affecting both the urban and the vast rural populations (over 600 million population of Indian states in the IGP).

While reductions in emissions are known to have led to significant air quality improvements across broad regions of Europe, North America, and East Asia $(35,36)$, the long-term rise in extreme smog over northern India is particularly concerning and in turn provides an opportunity to strengthen mitigation action. The northern Indian region, as part of the broader IGP, lies in a valley-type terrain immediately south of the towering Himalaya and so is naturally vulnerable to pollution build-up. Given the likely role of aerosol-radiation-meteorological feedbacks in worsening the widespread smog, expanding upon current air quality improvement efforts by accounting for pollution sources and transport processes across entire northern India, will support the development of a region-wide mitigation strategy. 


\section{Methods}

\section{Aerosol radiative forcing}

Data from the CERES instrument onboard Aqua satellite was used to characterize the radiative impact of aerosols on shortwave fluxes at the TOA and surface. The CERES observations were gridded onto a $0.25^{\circ} \times 0.25^{\circ}$ uniform grid on a daily basis and collocated with MODIS qualityassured Deep Blue AOD in space and time (best quality AOD retrievals were used to ensure stringent cloud filtering). For information related to MODIS and CERES data, refer to the datasets description in SI Appendix. The CERES derived fluxes were normalized by the cosine of solar zenith angle. In this study, northern India is divided into seven equal-spaced, $2^{\circ} \times 2^{\circ}$ grids, traversing from the western edge of the Gangetic Plains to the eastern flank (Fig. S6).

The clear-sky shortwave aerosol radiative forcing $(\Delta F)$ at the TOA and surface (SFC) is defined as the net change in shortwave radiative flux caused by aerosols which is calculated as:

$\triangle F_{T O A / S F C}=\left(F_{a}\right)_{T O A / S F C}-\left(F_{n a}\right)_{T O A / S F C}$

where, $F_{a}$ is the clear-sky shortwave flux at TOA and surface in the presence of aerosol-laden atmosphere (i.e. AOD $>0$ ). $F_{n a}$ represents the radiative fluxes without the presence of aerosols and is derived from the $y$-intercept (at AOD $=0$ ) of the linear regression between daily MODIS AOD and instantaneous CERES shortwave fluxes at the TOA and surface for each subregion and year, during the crop burning and winter haze (Fig. S6). This approach has been used in previous studies for characterizing direct radiative effect of aerosols $(37,38)$. The negative values of $\Delta F$ at surface imply that aerosols induce a cooling effect; whereas positive values at TOA are indicative of a brightening effect at TOA. $F_{n a}$ is computed only for those grid-cells where the number of data points is more than 10 and solar zenith angle less than $60^{\circ}$. In addition, the magnitude of solar radiation absorbed by aerosols within the atmosphere $\left(\Delta F_{a t m}=\Delta F_{T O A}-\Delta F_{S F C}\right)$ was computed, which defines the net atmospheric forcing (ATM) induced by aerosol absorption in the atmosphere. We also calculate the instantaneous atmospheric heating rate $(\mathrm{K} /$ day $)$, due to absorption of solar radiation by aerosols, based on the first law of thermodynamics and hydrostatics equilibrium as follows:

$$
\frac{\partial T}{\partial t}=\frac{g}{C_{p}} \times \frac{\Delta F_{a t m}}{\Delta P}
$$

where, $\partial \mathrm{T} / \partial \mathrm{t}$ is the heating rate $\left(\mathrm{K} /\right.$ day), $g$ is the acceleration due to gravity, $C_{p}$ is the specific heat capacity of air at constant pressure and $\Delta P$ is the atmospheric pressure difference between the top and bottom of the atmospheric layer in which most of the aerosol loading resides. Here, we consider the lowest $\sim 1.5 \mathrm{~km}$ tropospheric layer as the prominent aerosol layer during the crop burning and winter haze periods, as indicated by the vertical distribution analysis of aerosol extinction data (Fig. S9) from the NASA CALIPSO satellite's Cloud-Aerosol Lidar with Orthogonal Polarization (CALIOP data obtained from https://subset.larc.nasa.gov/calipso/).

In addition to the CERES and MODIS data derived instantaneous aerosol radiative forcing and heating rates, we also compute the diurnal mean (24-hour mean) aerosol radiative forcing and heating rates using a 1-dimensional plane-parallel radiative transfer model (RTM) (39). We used the observed relationship between TOA shortwave flux and AOD from CERES and MODIS data, respectively, specifically the slope and offset of the linear regression to constrain the RTMcalculated fluxes including the aerosol optical properties including single scattering albedo and asymmetry parameter. The aerosol optical properties were also constrained by data from ground- 
based column aerosol retrievals from NASA's AERONET sites in the IGP. Additionally, the aerosol vertical distribution input to the RTM was based on climatology of CALIPSO measurements (indicating most of the aerosol extinction with the surface to $\sim 1.5 \mathrm{~km}$ tropospheric layer). The RTM calculations were performed at every one degree increments of solar zenith angle to compute the radiative forcing and heating rate. The diurnal mean aerosol-induced heating rate averaged over the IGP for the 18-year period for the period 2002-2019 is $1.4 \mathrm{~K} /$ day $-1.6 \mathrm{~K} /$ day for the crop burning and winter haze periods. We find that the heating rate in the crop burning period has increased by $\sim 85 \%$ (to $2.1 \mathrm{~K} /$ day) and in the winter haze period by $\sim 37 \%$ (to $1.7 \mathrm{~K} /$ day) during the 18-year period. This enhancement in aerosol-induced heating in the lower troposphere, including the varying trend magnitudes by the different periods, are consistent with the observations of increase in AOD (mean and exceedances) as well as the aerosol-induced aerosol absorption, i.e. larger aerosol-induced absorption and heating trends in November relative to December-January (Fig. 2).

\section{Boundary layer height and frequency of temperature inversion}

The PBL height in the IGP, during the crop burning and winter haze periods, was derived using the bulk Richardson number $\left(R_{i}\right)$ method (40). The estimation of PBL height involved data obtained from NOAA IGRA as aforementioned in the SI Appendix Datasets section. Details of the bulk $R_{i}$ method and the criteria to derive PBL heights along with an uncertainty analysis and a comparison with other methods are discussed elsewhere (41). The following equation provides the main physical relationships involved in the computation of PBL heights:

$R i(z)=\frac{\left(g / \theta_{v s}\right)\left(\theta_{v z}-\theta_{v s}\right)\left(z-z_{S}\right)}{\left(\left(u_{z}-u_{S}\right)^{2}+\left(V_{z}-V_{S}\right)^{2}+\left(b u_{*}^{2}\right)\right.}$

where, $z$ is altitude of the atmospheric and $z_{s}$ denotes the surface altitude, $g$ is acceleration due to gravity, $\theta_{v}$ is virtual potential temperature, $u$ and $v$ are the horizontal components of the wind speed, $b$ is a constant and $u *$ is the surface friction velocity. Since $u *$ is not known from radiosonde data, we set $b=0$ and thus ignore surface friction effects, which are very small in comparison to the bulk shear terms in the denominator (40). The lowest level $z$ at which interpolated $R_{i}$ crosses the critical threshold value of 0.25 , determines the PBL height (41). For the estimation of PBL height, we used a threshold of at least five vertical levels available in daily radiosonde profiles greater than $500 \mathrm{hPa}$ (i.e. between ground and $500 \mathrm{hPa}$ ). Since the vertical distribution of wind measurements prior to year 2000 over several radiosonde sites over northern India have uneven or relatively sparse coverage, we considered the PBL height analysis from 2000 onwards. During the last two decades, the PBL height (in meters) was found to be associated with a decreasing trend of $-3.3 \pm 1.7 \mathrm{~m} \mathrm{yr}^{-1}$ (at $0 \mathrm{Z}$ or 5:30 am local-time) for the period 2000-2019, averaged for NovemberDecember-January over the five meteorological stations based on radiosonde observations. We also analysed MERRA-2 data over the entire northern India from and found an area-averaged trend of $-10.7 \pm 2.9 \mathrm{~m} \mathrm{yr}^{-1}$ for the period 1995-2019 (Fig. S12).

Regarding the computation of temperature inversion, the long-term data record and linear trends in the frequency of temperature inversion (i.e. number of inversion instances) in the lower troposphere was derived from daily radiosonde observations of temperature profiles over Delhi for the 40-year period 1980-2019, during the crop burning (November) and winter haze (December-January) periods. The trends in the frequency of temperature inversion events (Fig. 4C) indicate a twofold increase in inversion frequency during the last four decades for both November and December-January periods. The temperature inversion was calculated from 
temperature profiles within the lower troposphere only, defined here between ground-level and $700 \mathrm{hPa}$ (or upto $\sim 3 \mathrm{~km}$ above ground). The radiosonde observations correspond to 0Z (5:30 am local-time). The frequency of inversion (y-axis) represents the monthly count of the total number of detected inversion layers, in daily temperature profiles, which include both near-surface inversion and elevated inversion layers (i.e. all inversion layers detected within the lower troposphere). Note, multiple inversion layers can be present in a single radiosonde profile. The methodology for characterizing inversion layer is similar to Kahl et al. (42) and Gilson et al. (43). If one or more inversion layers are detected within $<100$ meters of the daily vertical temperature profile, those layers are considered as a single inversion layer.

\section{References}

1. A. Pandey et al., Health and economic impact of air pollution in the states of India: the Global Burden of Disease Study 2019. Lancet Planet. Heal. 5, e25-e38 (2021).

2. S. Chakrabarti, M. T. Khan, A. Kishore, D. Roy, S. P. Scott, Risk of acute respiratory infection from crop burning in India: Estimating disease burden and economic welfare from satellite and national health survey data for 250000 persons. Int. J. Epidemiol. 48, 1113-1124 (2019).

3. C. Venkataraman et al. Source influence on emission pathways and ambient PM 2.5 pollution over India (2015-2050). Atmos. Chem. Phys., 18, 8017-8039 (2018).

4. S. Chowdhury, S., Dey, S., Guttikunda, S., Pillarisetti, A., Smith, K. R., \& Di Girolamo, L. (2019). Indian annual ambient air quality standard is achievable by completely mitigating emissions from household sources. Proc. Natl. Acad. Sci. U.S.A, 116, 10711 10716.

5. A. R. Ravishankara, L. M. David, J. R. Pierce, C. Venkataraman, Outdoor air pollution in India is not only an urban problem. Proc. Natl. Acad. Sci. U.S.A, 117, 28640-28644 (2020).

6. P. Shyamsundar et al., Fields on fire: Alternatives to crop residue burning in India. Science 365, 536-538 (2019). doi:10.1126/science.aaw4085.

7. S. Bikkina, A. Andersson, E.N. Kirillova, H. Holmstrand, S. Tiwari, A.K. Srivastava, D.S. Bisht, Ö. Gustafsson, Air quality in megacity Delhi affected by countryside biomass burning. Nat. Sustain. 2, 200-205 (2019).

8. T. Liu, L.J. Mickley, R. Gautam, M.K. Singh, R.S. DeFries, M.E. Marlier, Detection of delay in post-monsoon agricultural burning across Punjab, India: potential drivers and consequences for air quality. Environ. Res. Lett. 16, 014014 (2021). doi:10.1088/17489326/abcc28.

9. D.H. Cusworth, L.J. Mickley, M.P. Sulprizio, T. Liu, M.E. Marlier, R.S. DeFries, S. Guttikunda, P. Gupta, Quantifying the influence of agricultural fires in northwest India on urban air pollution in Delhi, India. Environ. Res. Lett. 13, 044018 (2018).

10. Balwinder-Singh, A.J. McDonald, A.K. Srivastava, B. Gerard, Tradeoffs between groundwater conservation and air pollution from agricultural fires in northwest India. Nat. Sustain. 2, 580-583 (2019). https://doi.org/10.1038/s41893-019-0304-4. 
11. H. Jethva, O. Torres, R.D. Field, A. Lyapustin, R. Gautam, V. Kayetha, Connecting Crop Productivity, Residue Fires, and Air Quality over Northern India. Sci. Rep. 9, 16594 (2019). https://doi.org/10.1038/s41598-019-52799-x.

12. R. Kumar, S.D. Ghude, M. Biswas, C. Jena, S. Alessandrini, S. Debnath, S. Kulkarni, S. Sperati, V.K. Soni, R.S. Nanjundiah, M. Rajeevan, Enhancing accuracy of air quality and temperature forecasts during paddy crop residue burning season in Delhi via chemical data assimilation. J. Geophys. Res. Atmos. 125, e2020JD033019 (2020). https://doi.org/ 10.1029/2020JD033019.

13. R. Gautam, N.C. Hsu, M. Kafatos, S.C. Tsay, Influences of winter haze on fog/low cloud over the Indo-Gangetic plains. J. Geophys. Res. 112, D05207 (2007). https://doi.org/10.1029/2005JD007036.

14. X. Pan et al., A multi-model evaluation of aerosols over South Asia: common problems and possible causes. Atmos. Chem. Phys. 15, 5903-5928 (2015). https://doi.org/10.5194/acp-15-5903-2015, 2015.

15. S.D. Ghude et al., Winter fog experiment over the Indo-Gangetic plains of India. Curr. Sci. 112, 767- 784 (2016). https://doi.org/10.18520/cs/v112/i04/767-784.

16. C. Venkataraman, A. Sharma, K. Tibrewal, S. Maity, K. Muduchuru, "Carbonaceous Aerosol Emissions Sources Dominate India's Wintertime Air Quality”. EM (2019). https://pubs.awma.org/flip/EM-Dec-2019/venkataraman.pdf.

17. M. Gao, P. Sherman, S. Song, Y. Yu, Z. Wu, M. B. McElroy, Seasonal prediction of Indian wintertime aerosol pollution using the ocean memory effect. Sci. Adv. 5, eaav4157 (2019).

18. V.S. Nair, F. Giorgi, U.K. Hasyagar, Amplification of South Asian haze by water vapour-aerosol interactions. Atmos. Chem. Phys. 20, 14457-14471 (2020).

19. N. Ojha, A. Sharma, M. Kumar, I. Girach, T.U. Ansari, S.K. Sharma, N. Singh, A. Pozzer, S.S. Gunthe, On the widespread enhancement in fine particulate matter across the Indo-Gangetic Plain towards winter. Scientific reports, 10, 1-9 (2020).

20. CNN, "New Delhi is choking on smog and there's no end in sight" (4 November 2019 https://www.cnn.com/2019/11/04/india/delhi-india-smog-pollution-intlhnk/index.html).

21. National Geographic, "Pollution Is So Bad in India, It's Causing Car Crashes" (13 November 2017, YouTube video; https://www.youtube.com/watch?v=r_vQDa42tuM).

22. V. Ramanathan, P. J. Crutzen, J. T. Kiehl, D. Rosenfeld, Aerosols, climate, and the hydrological cycle. Science 294, 2119-2124 (2001).

23. Z. Li, J. Guo, A. Ding, H. Liao, J. Liu, Y. Sun, T. Wang, H. Xue, H. Zhang, B. Zhu, Aerosol and boundary-layer interactions and impact on air quality. National Science Review 4, 810-833 (2017).

24. Z. An, R. J. Huang, R. Zhang, X. Tie, G. Li, J. Cao, W. Zhou, Z. Shi, Y. Han, Z. Gu, Y. $\mathrm{Ji}$, Severe haze in northern China: A synergy of anthropogenic emissions and atmospheric processes. Proc. Nat. Acad. Sciences 116, 8657-8666 (2019). 
25. D.G. Kaskaoutis, S. Kumar, D. Sharma, R.P. Singh, S.K. Kharol, M. Sharma, A.K. Singh, S. Singh, A. Singh, D. Singh, Effects of crop residue burning on aerosol properties, plume characteristics, and long-range transport over northern India. $J$. Geophys. Res. Atmos. 119, 5424-5444 (2014). https://doi.org/10.1002/2013JD021357.

26. Z. Li, L. Li, F. Zhang, D. Li, Y. Xie, H. Xu, Comparison of aerosol properties over Beijing and Kanpur: Optical, physical properties and aerosol component composition retrieved from 12 years ground-based Sun-sky radiometer remote sensing data. $J$. Geophys. Res. Atmos. 120, 1520- 1535 (2015).

27. R. Wood, C.S. Bretherton, On the relationship between stratiform low cloud cover and lower-tropospheric stability. J. Clim. 19, 6425-6432 (2006).

28. A.K. Ambika, V. Mishra, Substantial decline in atmospheric aridity due to irrigation in India. Environ. Res. Lett. 15124060 (2020).

29. CNN, "United suspends flights to smog-filled Delhi" (10 November 2017 https://money.cnn.com/2017/11/10/news/delhi-pollution-united-flights/index.html).

30. The Guardian, "Pollution stops play at Delhi Test match as bowlers struggle to breathe. (3 December 2017; https://www.theguardian.com/world/2017/dec/03/pollution-stopsplay-at-delhi-test-match-as-bowlers-struggle-to-breathe).

31. The Hindu, "States should stop blaming each other on stubble burning, need to take it seriously: Arvind Kejriwal" (13 October 2020; https://www.thehindu.com/news/cities/Delhi/states-should-stop-blaming-each-other-onstubble-burning-need-to-take-it-seriously-arvind-kejriwal/article32843377.ece).

32. M.E. Miro, M.E. Marlier, R.S. Girven, "Transboundary Environmental Stressors on India-Pakistan Relations: An Analysis of Shared Air and Water Resources" (RAND Corporation, 2019; https://www.rand.org/pubs/research_reports/RR2715.html).

33. Y. Zou, Y. Wang, Y. Zhang, J.-H. Koo, Arctic sea ice, Eurasia snow, and extreme winter haze in China. Sci Adv. 3, e1602751 (2017).

34. The Gazette of India, Extraordinary, "The Commission for Air Quality Management In National Capital Region And Adjoining Areas Ordinance, 2020" (CG-DL-E-28102020222804, Part II - Section 1, 2020; http://www.egazette.nic.in/WriteReadData/2020/222804.pdf).

35. R. Vautard, P. Yiou, G.J. van Oldenborgh, Decline of fog, mist and haze in Europe over the past 30 years. Nat. Geosci. 2, 115-119 (2007). https://doi.org/10.1038/ngeo414.

36. M.S. Hammer et al., Global Estimates and Long-Term Trends of Fine Particulate Matter Concentrations (1998-2018). Environ. Sci. Technol. 54, 7879-7890 (2020). doi:10.1021/acs.est.0c01764.

37. N.C. Hsu, J.R. Herman, C. Weaver, Determination of radiative forcing of Saharan dust using combined TOMS and ERBE data. J. Geophys. Res. Atmos. 105, 20649-20661 (2000).

38. R. Gautam, N.C. Hsu, T.F. Eck, B.N. Holben, S. Janjai, T. Jantarach, S.C. Tsay, W.K. Lau, Characterization of aerosols over the Indochina peninsula from satellite-surface observations during biomass burning pre-monsoon season. Atmos. Environ. 78, 51-59 
(2013).

39. P. Ricchiazzi, S. Yang, C. Gautier, D. Sowle, SBDART: A research and teaching software tool for plane-parallel radiative transfer in the Earth's atmosphere. Bulletin Amer. Meteorol. Soc. 79, 2101-2114 (1998).

40. P. Seibert, F. Beyrich, S.E. Gryning, S. Joffre, A. Rasmussen, P. Tercier, Review and intercomparison of operational methods for the determination of the mixing height. Atmos. Environ., 34, 1001-1027 (2000).

41. D.J. Seidel, Y. Zhang, A. Beljaars, J.-C. Golaz, A.R. Jacobson, B. Medeiros, Climatology of the planetary boundary layer over the continental United States and Europe, J. Geophys. Res. 117, D17106 (2012). doi:10.1029/2012JD018143.

42. J.D. Kahl, M.C. Serreze, R.C. Schnell, Tropospheric low-level temperature inversions in the Canadian Arctic. Atmosphere-Ocean 30, 511-529 (1992).

43. G.F. Gilson, H. Jiskoot, J.J. Cassano, T.R. Nielsen, Radiosonde-Derived Temperature Inversions and Their Association With Fog Over 37 Melt Seasons in East Greenland. $J$. Geophys. Res. Atmos., 123, 9571-9588 (2018).

Data availability: All data underlying this study are available in the public domain. The MODIS data used in this study are available via http://dx.doi.org/10.5067/MODIS/MYD04_L2.006 and CERES data are available via https://doi.org/10.5067/Aqua/CERES/SSF-FM3_L2.004A. We have provided links to the various data access portals in the SI Appendix Datasets description section for each of the satellite dataset, ground-based observations and modeling-based reanalysis datasets used in this study. 

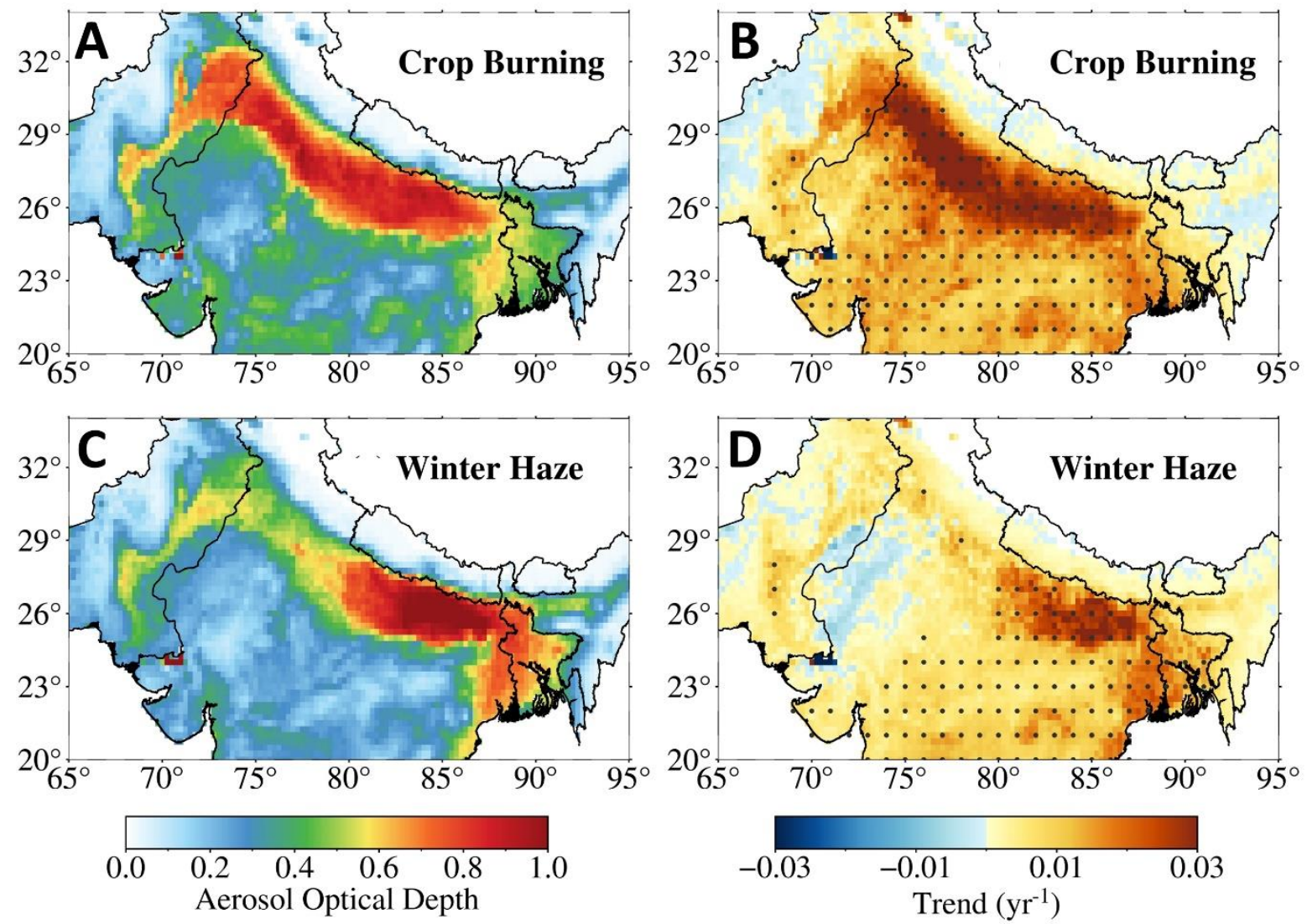

Figure 1. Aerosol distribution and trends over south Asia during the last two decades using satellite data. Aerosol optical depth (AOD) for crop burning (November) and winter haze (December-January) periods in (A) and (C), averaged from 2002-2019, using Aqua/MODIS observations. The AOD (unitless) is largest along the Indo-Gangetic Plains indicated by the warm shading. The corresponding linear trends in AOD $\left(\mathrm{yr}^{-1}\right)$ are shown in $(\mathbf{B})$ and $(\mathbf{D})$, with dots indicating statistical significance of trends at $95 \%$ confidence level. 

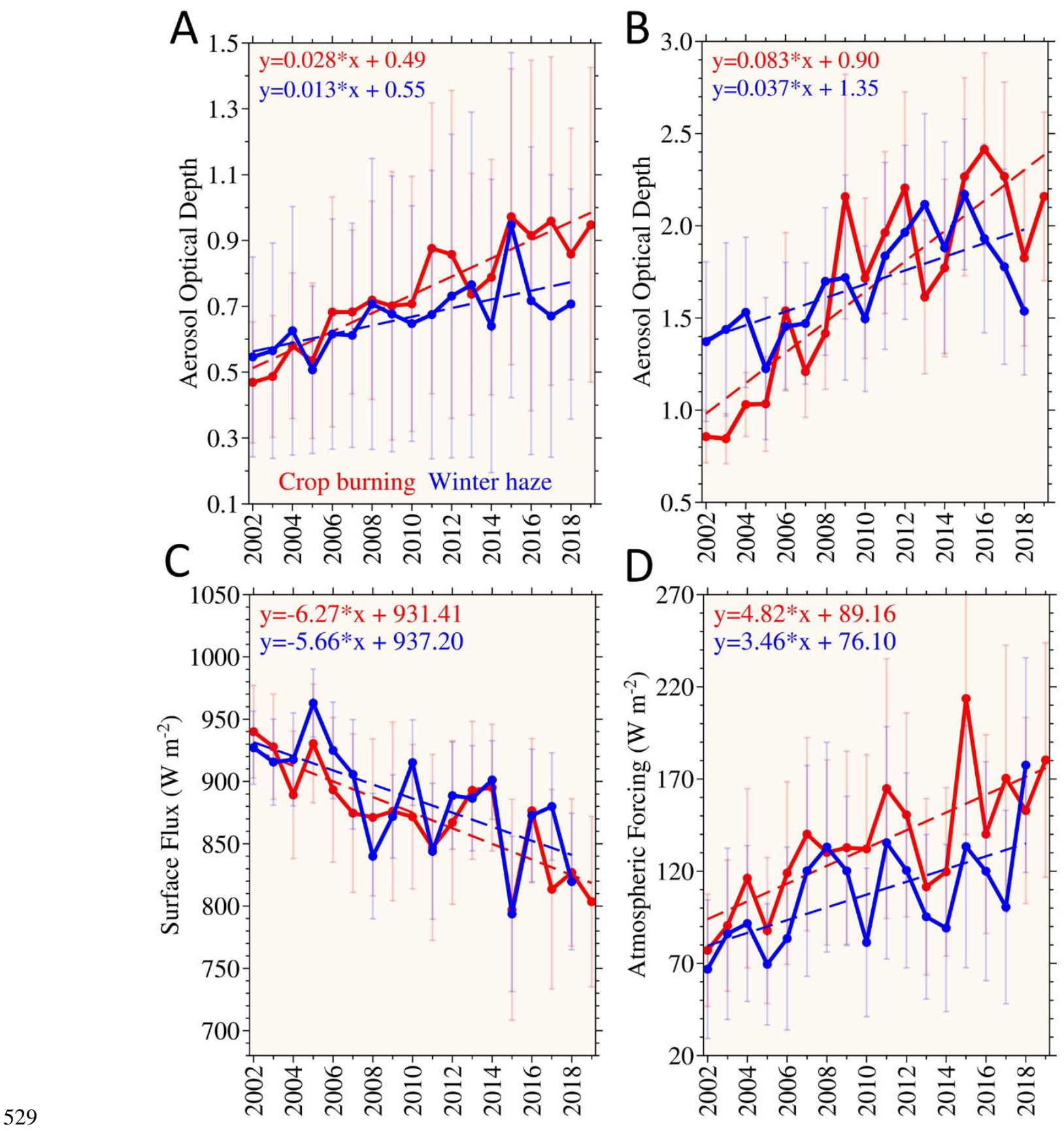

Figure 2. Trends in aerosol extremes, aerosol-induced surface cooling and atmospheric warming. Time series and linear trends for $(\mathbf{A})$ mean and $(\mathbf{B})$ exceedance AOD, averaged over the Indo-Gangetic Plains for crop burning (red) and winter haze (blue) periods from 2002 to 2019. The corresponding trends in cloud-free collocated instantaneous shortwave fluxes, derived from Aqua/CERES observations, are shown in $(\mathbf{C})$ surface cooling $\left(\mathrm{W} / \mathrm{m}^{2}\right)$ and $(\mathbf{D})$ atmospheric forcing $\left(\mathrm{W} / \mathrm{m}^{2}\right)$ averaged over northern India. Error bars indicate \pm 1 standard deviation. 


\section{A Lower Tropospheric Stability (mean)}
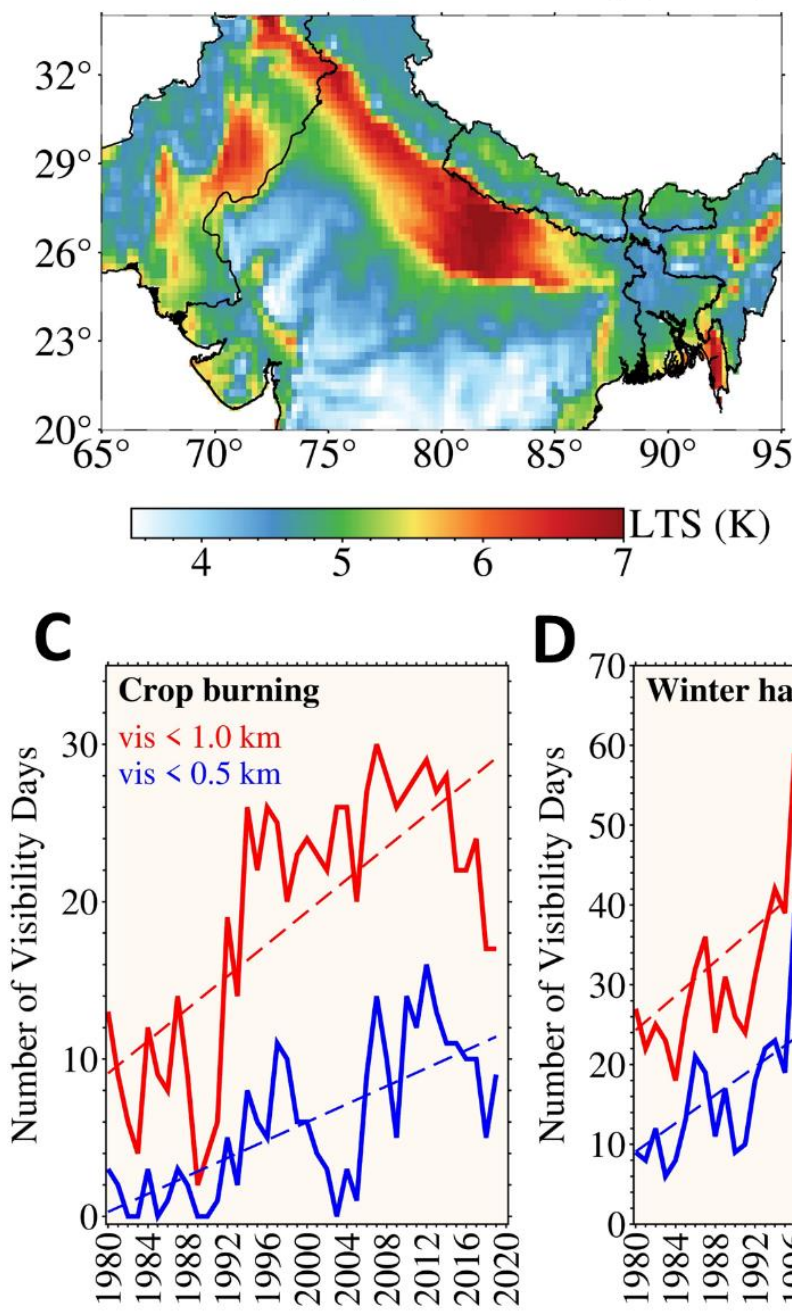

D
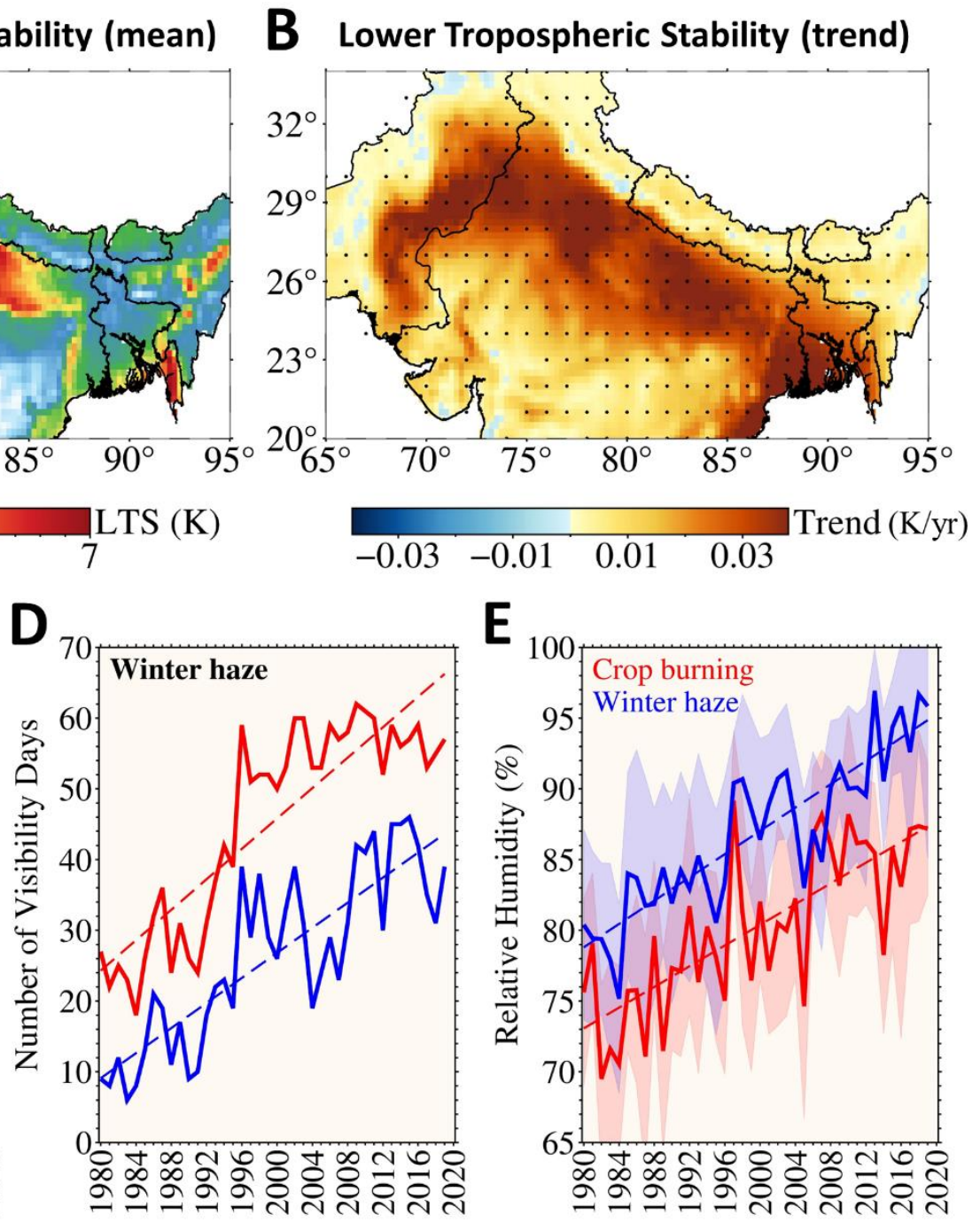

E

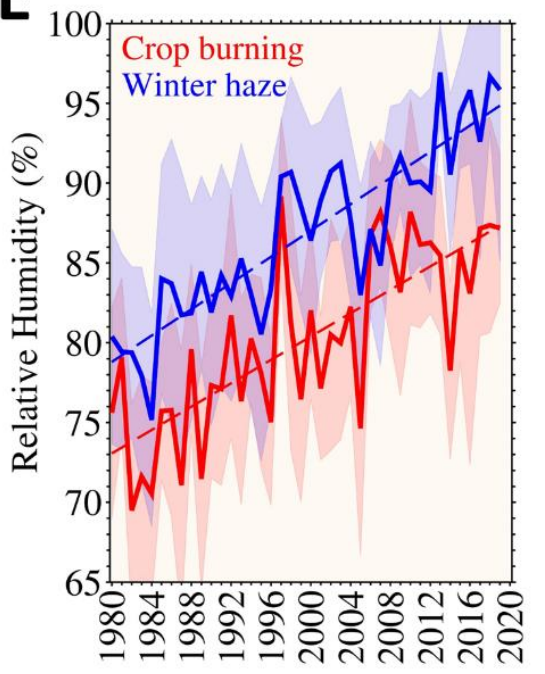

Figure 3. Lower tropospheric stability (LTS) and long-term trends in smog. The LTS is shown as (A) the multidecadal average and (B) spatial trend, from November-January for the period 1980-2019, with significantly increasing LTS along the IGP. Dots in (b) indicate statistical significance of trends at $95 \%$ confidence level. Number of visibility days during (C) crop burning in November (out of 30 days) and (D) winter haze in December-January (out of 62 days) over Delhi. Visibility $<1 \mathrm{~km}$ is shown in red and $<0.5 \mathrm{~km}$ in blue. The monthly mean relative humidity (e) is shown for crop burning (red) and winter haze (blue) periods. Shading represents \pm 1 standard deviation. 

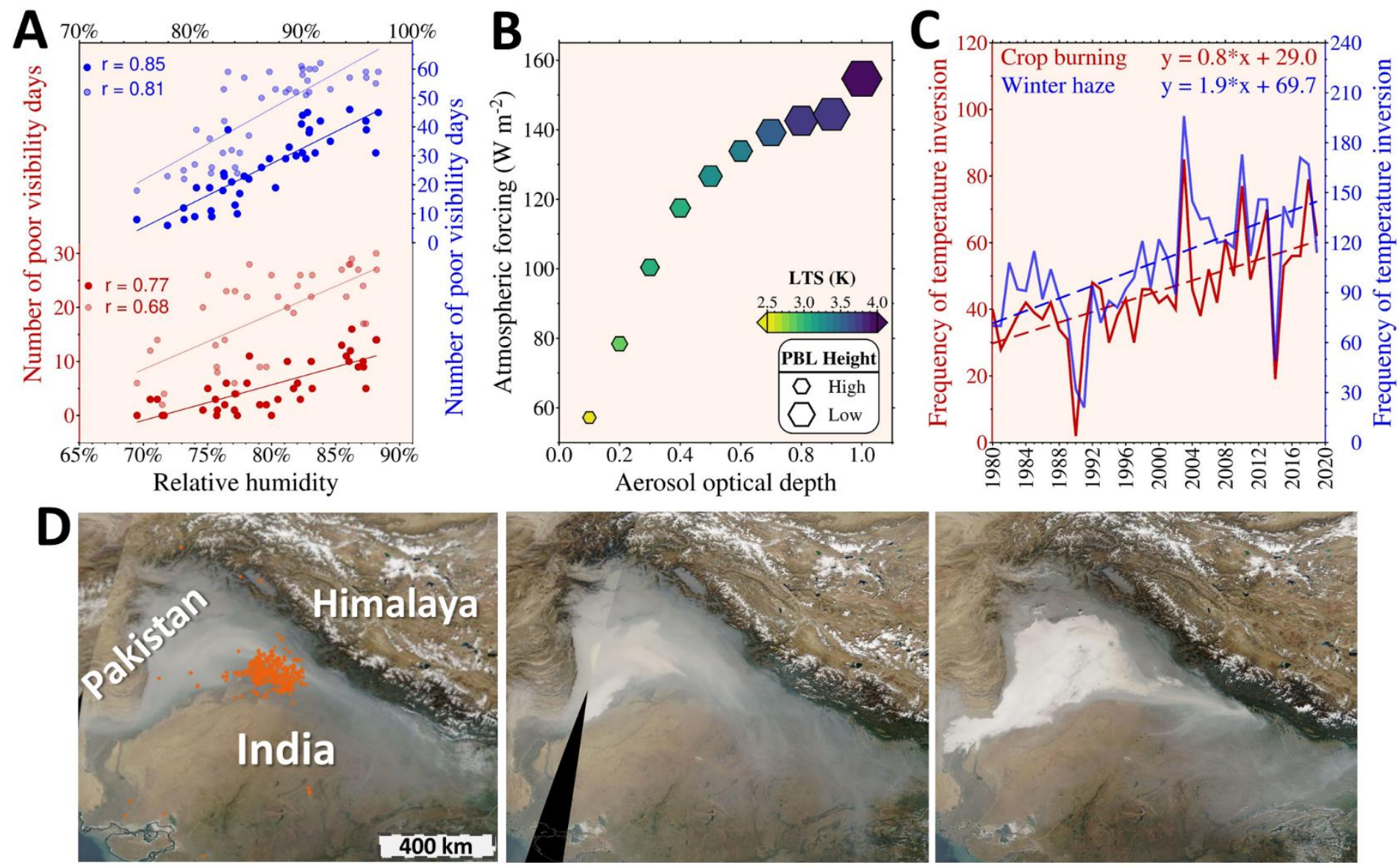

5 5

Nov. 1

Nov. 3

Nov. 6

Figure 4. Evolution of smog blanketing southern Asia and aerosol-radiation-meteorological interactions. (A) Correlation between number of poor visibility days and monthly mean relative humidity for the period 1980-2019, based on surface meteorological observations over Delhi, for November (red color, left y-axis) and December-January (blue color, right $\mathrm{y}$-axis). The number of visibility days $<1 \mathrm{~km}$ is shown in light red (November) and light blue (December-January), whereas number of visibility days <0.5 $\mathrm{km}$ are shown in dark red (November) and dark blue (December-January). Correlation is higher for visibility $<0.5 \mathrm{~km}$ for both time periods $(r$ : $0.77-0.85, p$-value $<<0.01)$ suggesting enhanced poor visibility degradation under humid conditions. (B) Aerosol-induced atmospheric forcing (or atmospheric absorption) in $\mathrm{Wm}^{-2}$ plotted as a function of aerosol optical depth derived from CERES and MODIS satellite observations, corresponding to lower tropospheric stability (LTS) (indicated by shading of the hexagon symbols) and planetary boundary layer height (meters) indicated by the size of the colored symbols. The aerosol-induced atmospheric forcing increases with aerosol optical depth along with an increase in LTS which strengthens at lower PBL heights (shallow boundary layer) and weakens at larger PBL heights (deeper boundary layer). (C) Time series and linear trends in the frequency of temperature inversion (i.e. monthly count of the total number of detected inversion layers, in daily radiosonde observations) in the lower troposphere over Delhi from 1980 to 2019, for November (red) and December-January (blue). (D) An illustrative depiction of the evolution of smog in the Indo-Gangetic Plains, south of the Himalaya, encompassing Pakistan, northern India and Nepal. Satellite imagery (Terra/MODIS) is from 1, 3 , 6 November 2017 acquired at 10:30 am local-time. Orange dots on 1 November show fire detections from Aqua/MODIS satellite observations (1:30 pm local-time). 
590

591

592

593

594

595

596

597

598

599

600

601

602

603

604

605

606

607

608

609

610

611

612

613

614

615

616

617

\title{
Supplementary Information for
}

\section{Extreme smog challenge of India intensified by increasing lower tropospheric stability}

\author{
Ritesh Gautam*, Piyushkumar N. Patel, Manoj K. Singh, Tianjia Liu, Loretta J. Mickley, Hiren Jethva, \\ Ruth S. DeFries \\ *Corresponding author. Email: rgautam@edf.org
}

\section{This PDF file includes:}

Supplementary text

Figures S1 to S13

SI References 


\section{Supplementary Text: Datasets}

We used two decades of multi-satellite observations to characterize trends in aerosol optical depth (AOD) and associated aerosol-induced radiative forcing during crop burning (November) and winter haze periods (December-January) over northern India.

\section{Moderate resolution Imaging Spectroradiometer (MODIS) AOD data-}

We used the $10 \mathrm{~km}$ x $10 \mathrm{~km}$ spatial resolution MODIS Level-2 Collection 6.1 (C061) qualityassured daily aerosol retrievals (MOD04 and MYD04) at $550 \mathrm{~nm}$ from both Terra (20 years; 20002019) and Aqua (18 years; 2002-2019) over the Indo-Gangetic Plains (IGP). The Terra local overpass time is $\sim 10: 30$ am and Aqua is $\sim 1: 30 \mathrm{pm}$. We used AOD retrievals from the Deep Blue (DB) algorithm for characterizing the climatology and trends in AOD during crop burning (November) and winter haze (December-January) periods. The uncertainty for DB AOD retrievals is reported as $\pm(0.03+0.2 \tau)(1)$, where $\tau$ represents AOD. Details of the DB AOD data product are available at-

https://modis-

attmos.gsfc.nasa.gov/sites/default/files/ModAtmo/modis_deep_blue_c61_changes.pdf.

We computed exceedances in AOD which are defined here as the mean of daily pixel-level data found above +1 standard deviation of the spatial mean AOD computed individually for each time period (i.e. separately for crop burning and winter haze periods), and then repeated for each year. These AOD exceedances were analysed for their trends to characterize long-term changes in extreme aerosol pollution over the IGP using Aqua and Terra MODIS observations during the past two decades (as depicted in Fig. 2b and Fig. S3). The MODIS aerosol data used in this study is available from: https://ladsweb.modaps.eosdis.nasa.gov/.

\section{Clouds and the Earth's Radiant Energy System (CERES) data-}

To characterize changes in aerosol-induced radiative effects, the most recent Edition 4 CERES Single Scanner Footprint (SSF) Level-2 data product, from Aqua satellite at $20 \mathrm{~km}$ x $20 \mathrm{~km}$ horizontal resolution at nadir (18 years; 2002-2019), is used for evaluating the impacts of aerosol loading on clear-sky top-of-atmosphere (TOA) and surface shortwave radiative fluxes during crop burning and winter haze periods. The Aqua/CERES daytime overpass is $\sim 1: 30 \mathrm{pm}$ local-time. The CERES instrument measures radiance at a given Sun-satellite geometry, which is then converted to radiative flux using angular distribution models. More details about the CERES instrument and its calibration are discussed elsewhere (2). The averaged TOA instantaneous shortwave flux uncertainty is reported to be $1.6 \%\left(4.5 \mathrm{~W} \mathrm{~m}^{-2}\right)$ for cloud-free scenes over land surfaces (3). Instantaneous footprints of TOA radiances are operationally used as a constraint to compute the surface radiative fluxes following the NASA Langley Fu-Liou radiative transfer model. The CERES-derived surface fluxes have been extensively validated over the past two decades against ground-based shortwave flux measurements from high-quality surface networks. The uncertainty in the cloud-free surface flux data product based on global assessment (4) is associated with a systematic error of $-0.6 \mathrm{~W} \mathrm{~m}^{-2}(-0.1 \%)$ and a random error of $37.5 \mathrm{~W} \mathrm{~m}^{-2}(6.1 \%)$, with the relative error as included in the parenthesis. For continental scenes, the cloud-free surface flux uncertainty is reported with a systematic error of $6.3 \mathrm{~W} \mathrm{~m}^{-2}(0.9 \%)$ and random error of $49.9 \mathrm{~W} \mathrm{~m}^{-2}(7.1 \%)$ (40). More information about the CERES SSF data product is available at: https://asdc.larc.nasa.gov/documents/ceres/quality_summaries/CER_SSF_Terra- 
660 Aqua_Edition4A.pdf. The CERES SSF data used in this study is available from:

661 https://ceres.larc.nasa.gov/data/\#ssf-level-2.

662 European Centre for Medium-Range Weather Forecasts (ECMWF) ERA5 reanalysis data-

663 To examine long-term trends in the lower tropospheric stability over the IGP, we used reanalysis 664 meteorological fields from the ECMWF ERA5 dataset. The reanalysis is produced using the 665 Integrated Forecast System (IFS) cycle 41r2 with 4D-Var data assimilation, as released in 2016. 666 ERA5 has a horizontal resolution of $0.25^{\circ} \times 0.25^{\circ}$, available at 137 hybrid sigma pressure levels 667 in the vertical domain (from 1000 to $0.01 \mathrm{hPa}$ ). Details about the atmospheric models, assimilation

668

669

670

671

672

673

674

675

676

677

678

679

680

681

682

683

684

685

686

687

688

689

690

691

692

693

694 methodology, improvements and quality of the data are extensively discussed elsewhere (5). In this study, we extracted the air temperature data for three different pressure levels $(700 \mathrm{hPa}, 850 \mathrm{hPa}$ and $1000 \mathrm{hPa}$ ) to derive lower tropospheric stability at $700 \mathrm{hPa}$ and $850 \mathrm{hPa}$. The ERA5 data is available from: https://www.ecmwf.int/en/forecasts/datasets/reanalysis-datasets/era5.

\section{Radiosonde data \& ground-based observations}

Radiosonde observations are obtained from the NOAA land-based radiosonde station network Integrated Global Radiosonde Archive (IGRA) (6). For this study, we used the enhanced version 2 of IGRA database (7) which contains data on temperature, geopotential height, relative humidity and wind at various atmospheric pressure levels, as well as additional derived moisture variables and calculated vertical gradients of several other variables. A detailed description of the IGRA datasets as well as information on quality assurance are discussed elsewhere (6). We used radiosonde data at 5 locations throughout northern India (Patiala $-30.33^{\circ} \mathrm{N} / 76.47^{\circ} \mathrm{E}$, Safdarjung - $28.58^{\circ} \mathrm{N} / 77.2^{\circ} \mathrm{E}$, Gorakhpur - $26.75^{\circ} \mathrm{N} / 83.37^{\circ} \mathrm{E}$, Lucknow - $26.75^{\circ} \mathrm{N} / 80.88^{\circ} \mathrm{E}$, Patna $25.6^{\circ} \mathrm{N} / 85.17^{\circ} \mathrm{E}$ ), representing observations from the western end of the Gangetic Plains (Patiala) to the eastern portion (Patna) to assess trends in the planetary boundary layer (PBL) height. We also obtained PBL data from NASA's Modern-Era Retrospective analysis for Research and Applications, version 2 (MERRA-2) to additionally analyze long-term changes in PBL over the IGP; MERRA-2 data are available from https://gmao.gsfc.nasa.gov/reanalysis/MERRA-2/.

Additionally, we used ground-based weather station data at five sites (as mentioned above) from northern India to characterize long-term trends in visibility and relative humidity (RH) for the period 1980-2019, based on surface meteorological observations from the global archive data obtained from NOAA's National Climatic Data Center's Climate Data Online program (https://www.ncdc.noaa.gov/cdo-web/).

Finally, we also used Multi-angle Imaging Spectro-Radiometer (MISR) Level-3 AOD data at $0.5^{\circ} \times 0.5^{\circ}$ (https://giovanni.gsfc.nasa.gov/giovanni/) and AERONET level-2 AOD data from Kanpur (https://aeronet.gsfc.nasa.gov/). 


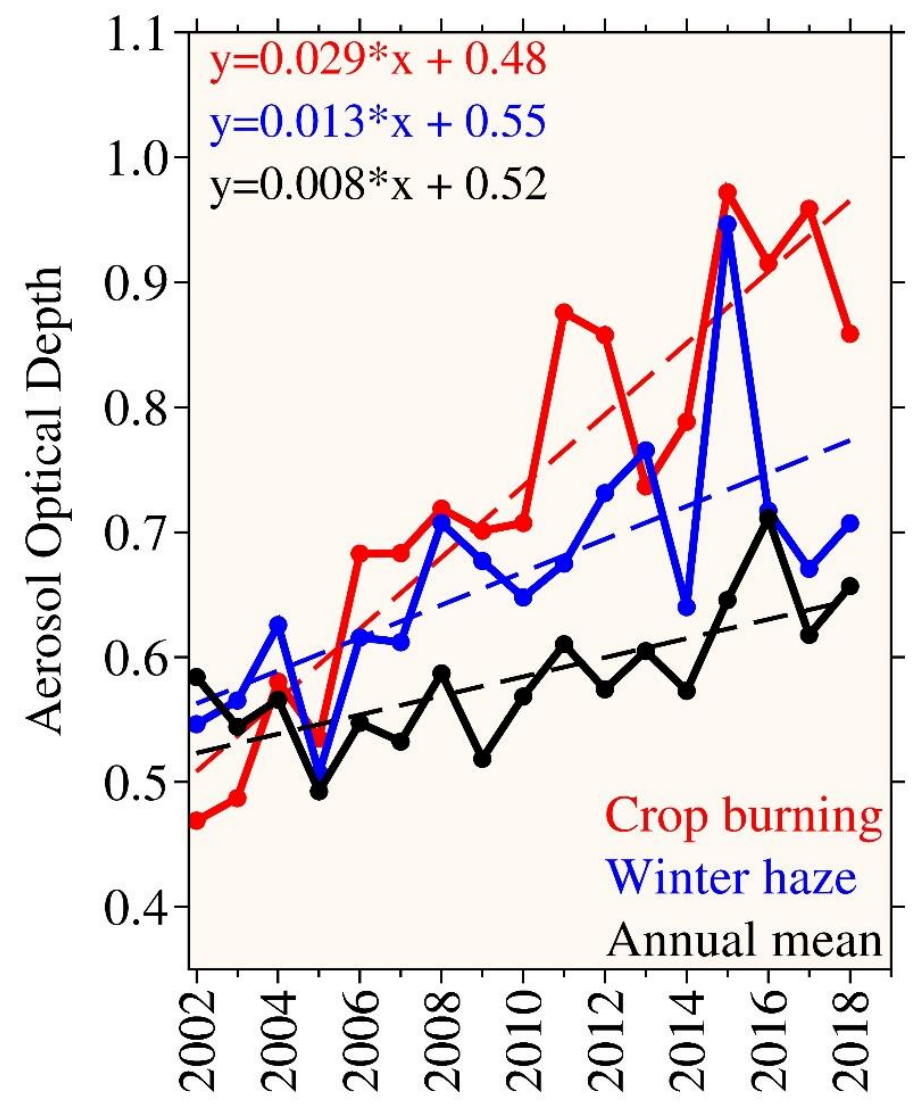

Fig. S1. Aerosol trends over northern India using satellite data. Time-series and linear trends for AOD averaged during crop burning (November in red), winter haze (December-January in blue) and annual (12 months from January to December) periods over the IGP for the period 2002 to 2018, derived using Aqua/MODIS data. The trend value in crop burning period is $>3$ times larger than the annual mean trend, whereas the winter haze trend is $>1.5$ times larger than the annual mean trend.

3

5

6

8



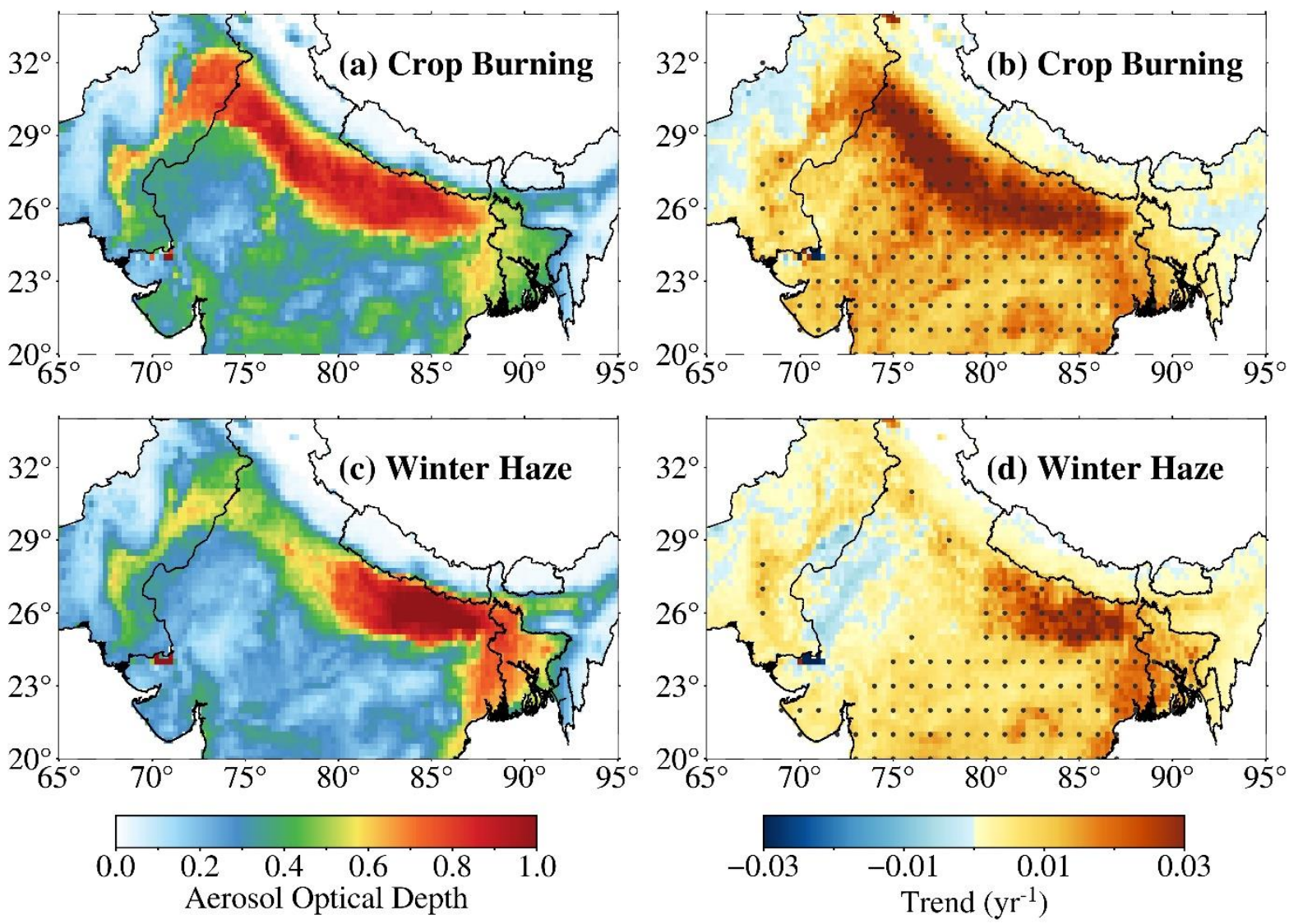

Fig. S2. Distribution and trends in smog over south Asia during the last two decades using satellite data. Multi-year averaged aerosol optical depth (AOD) for crop burning (November) and winter haze (December-January) periods shown in (a) and (c) for the period 2000-2019, derived using Terra/MODIS observations. The AOD (unitless quantity) is largest across the IGP, as indicated by the warm shading. The corresponding linear trends in AOD (per year) for the 20-year period are shown in (b) and (d), with dots indicating statistical significance of trends at $95 \%$ confidence level. 
(a) Mean AOD

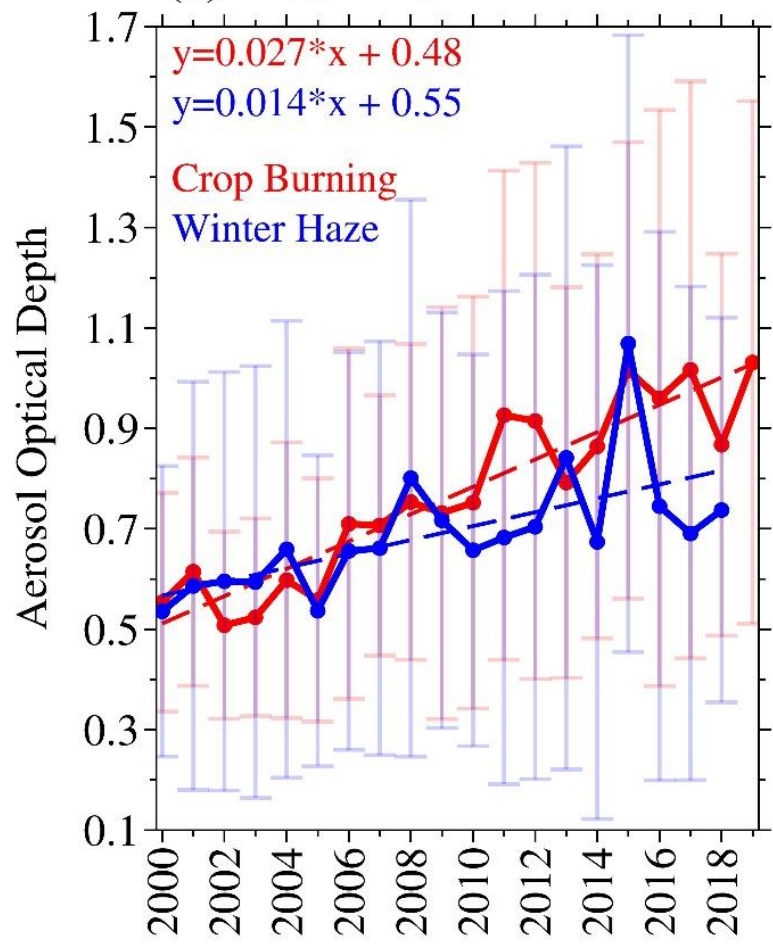

(b) Exceedance AOD

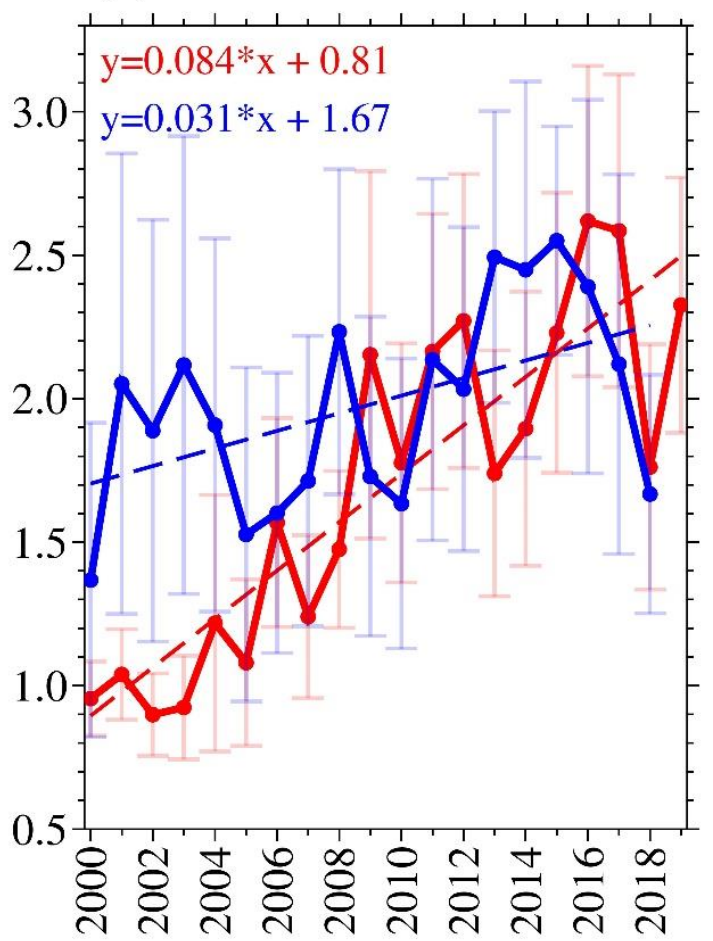

Fig. S3. Trends in aerosol extremes and aerosol-induced surface cooling and atmospheric warming. Time series and linear trends for (a) mean AOD and (b) exceedance AOD, derived from Terra MODIS data, averaged over the IGP for crop burning (red) and winter haze (blue) months from 2000 to 2019. Error bars indicate \pm 1 standard deviation. 

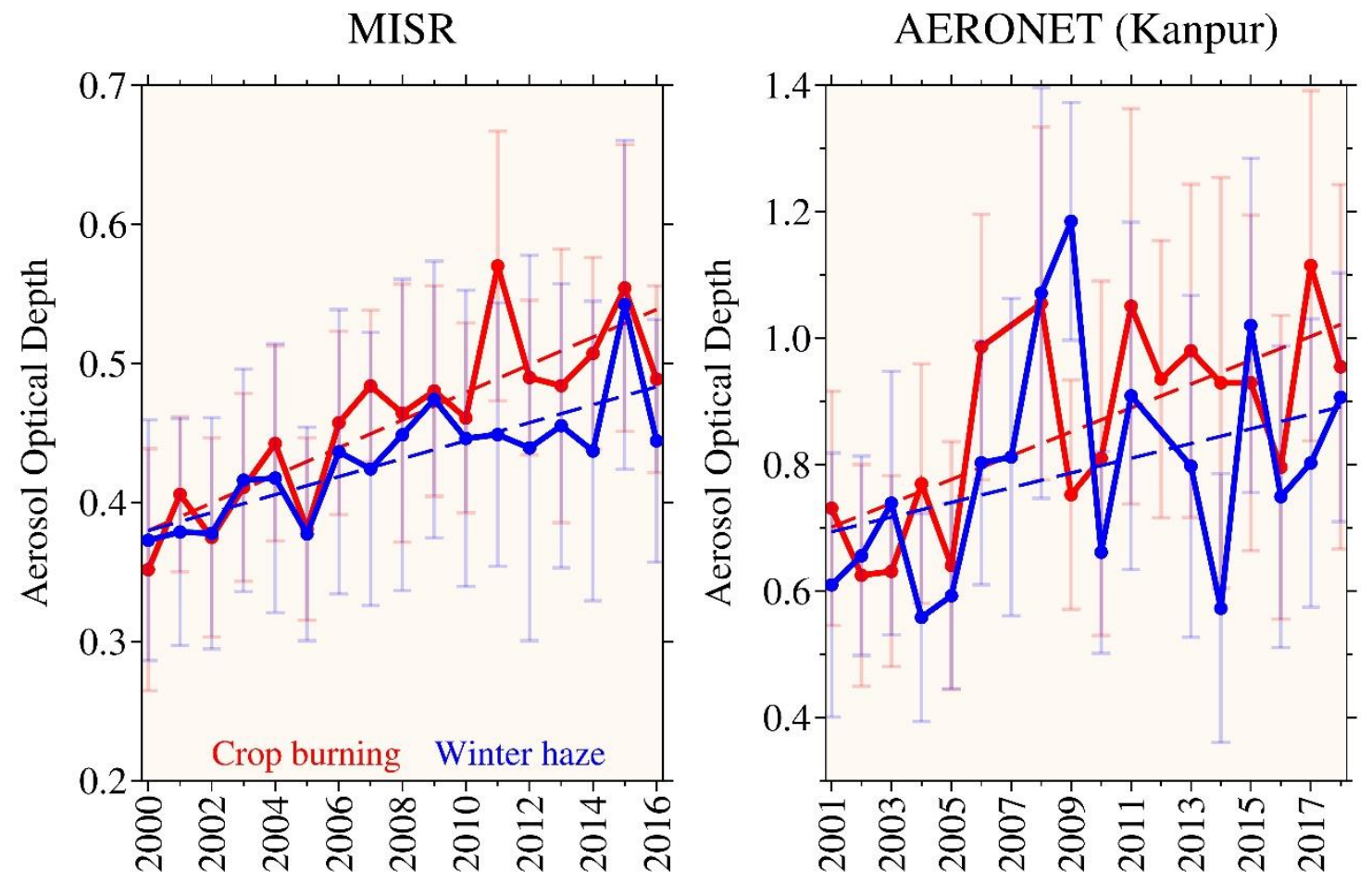

Fig. S4. Aerosol trends over northern India from MISR and ARONET data. Time-series of aerosol optical depth (AOD) averaged over the IGP during crop burning and winter haze periods from (left panel) the spaceborne Multiangle Imaging Spectroradiometer (MISR) and (right panel) the ground-based measurements from Aerosol Robotic Network (AERONET) measurements in Kanpur. Linear regression equation shows trend (slope as $\mathrm{AOD} \mathrm{yr}^{-1}$ ) and offset values. 


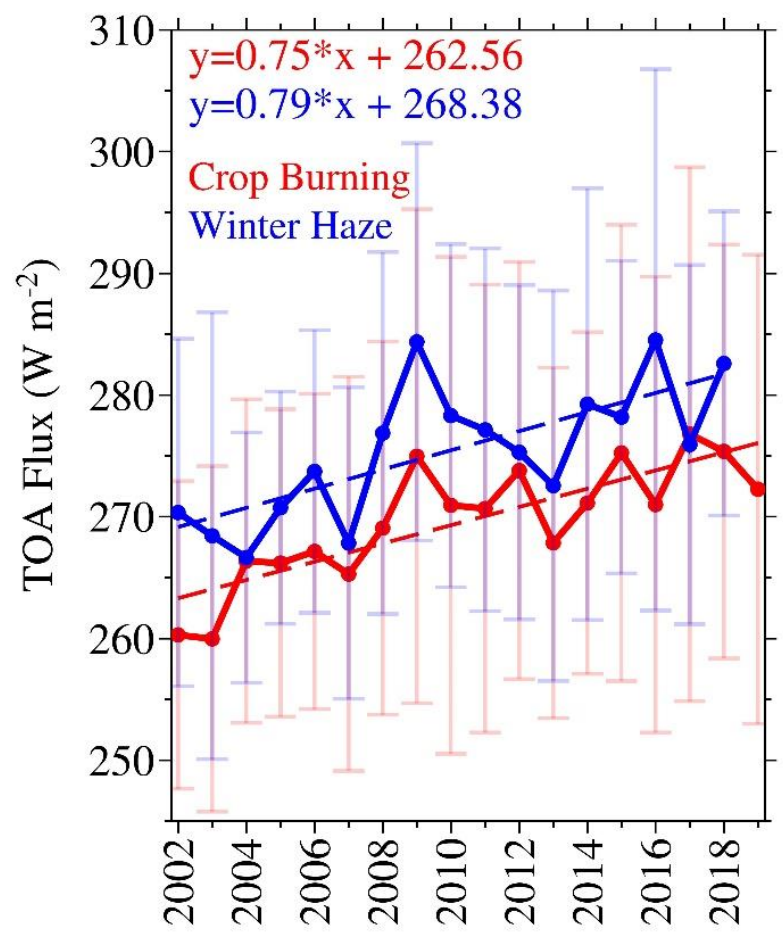

743 Fig. S5. Changes in TOA shortwave flux over northern India. Aerosol-induced changes in 744 instantaneous top-of-atmosphere TOA shortwave flux $\left(\mathrm{Wm}^{-2}\right)$ averaged over the IGP during crop 745 burning (red) and winter haze (blue) periods. TOA flux observations are obtained from CERES 746 data, as described in the Methods and SI Appendix Datasets sections. The TOA flux follows an 747 increasing trend for both crop burning and winter haze periods, as indicated by the linear 748 regression. Error bars correspond to \pm 1 standard derivation. 

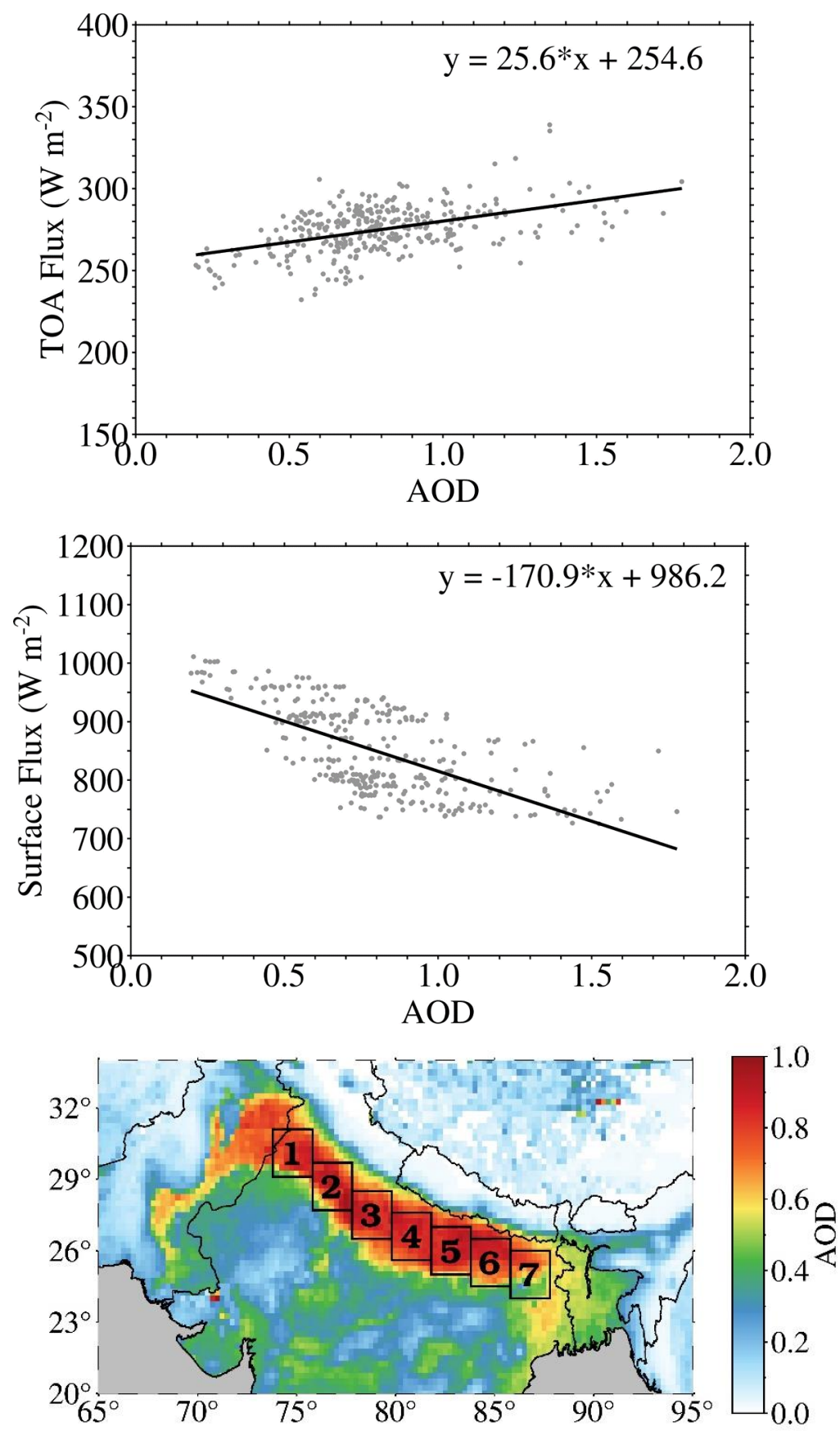

Fig. S6. Aerosol radiative forcing at TOA and surface. Example of the relationship between instantaneous top-of-atmosphere (TOA) reflected shortwave flux, surface-reaching shortwave flux and aerosol optical depth (AOD) over a $2^{\circ}$ x $2^{\circ}$ area \#3 (shown in the bottom panel of this Figure) from northern India during the 2018 crop burning period (November). The TOA flux and AOD data were gridded to a quarter degree spatial resolution with cloud-screening applied to the TOA flux data. The brightening effect at TOA (top) is observed with enhancement in TOA flux as a function of increasing AOD; (middle) whereas a robust cooling effect is derived for surfacereaching shortwave flux as a function of increasing AOD. 

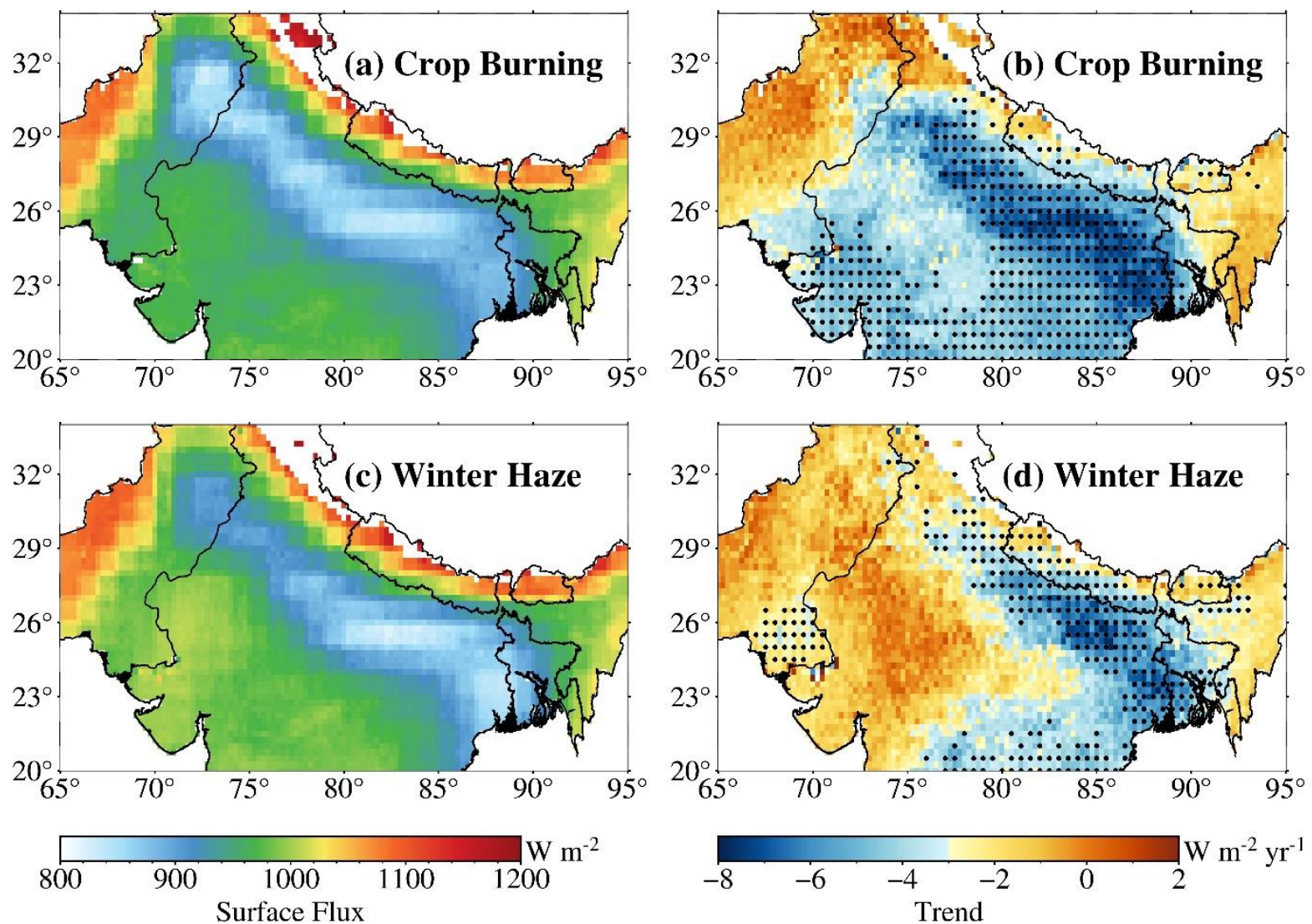

764 Fig. S7. Climatology and trends in aerosol-induced surface cooling. Climatology of spatial distribution of instantaneous CERES satellite data-derived surface radiative flux averaged for the (a) crop burning and (c) winter haze periods. The radiative flux data are screened for clouds and therefore represent aerosol-induced surface cooling. The long-term climatological impact of aerosols extinction (scattering + absorption) is largest over northern India where we find the largest reduction in surface-reaching shortwave radiation (shades of white to blue), relative to other regions of southern Asia. The corresponding linear trends $\left(\mathrm{W} \mathrm{m}^{-2} \mathrm{yr}^{-1}\right)$ are shown in (b) and (d) for crop burning and winter haze periods, respectively. CERES data period for the climatology maps and trend analysis is 2002-2019. Black dots represent the statistical significance of the linear trends at $95 \%$ confidence level. 


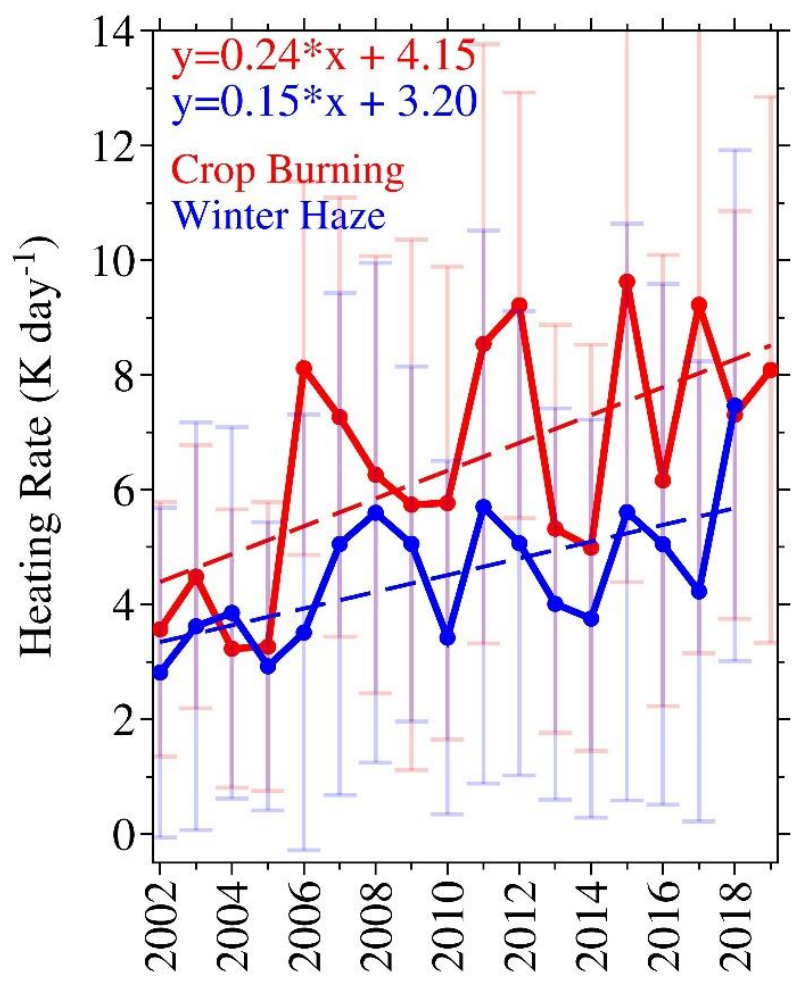

Fig. S8. Trends in aerosol-induced heating rate. Aerosol-induced instantaneous atmospheric heating rate $\left(\mathrm{K} \mathrm{day}^{-1}\right)$ averaged over the Indo-Gangetic Plains during crop burning (red) and winter haze (blue) periods, derived from atmospheric forcing computed with direct inputs from CERES data, as described in the Methods and SI Appendix Datasets sections. The heating rate follows an increasing trend for both crop burning winter haze periods, as indicated by the linear regression. Error bars correspond to \pm 1 standard derivation. 


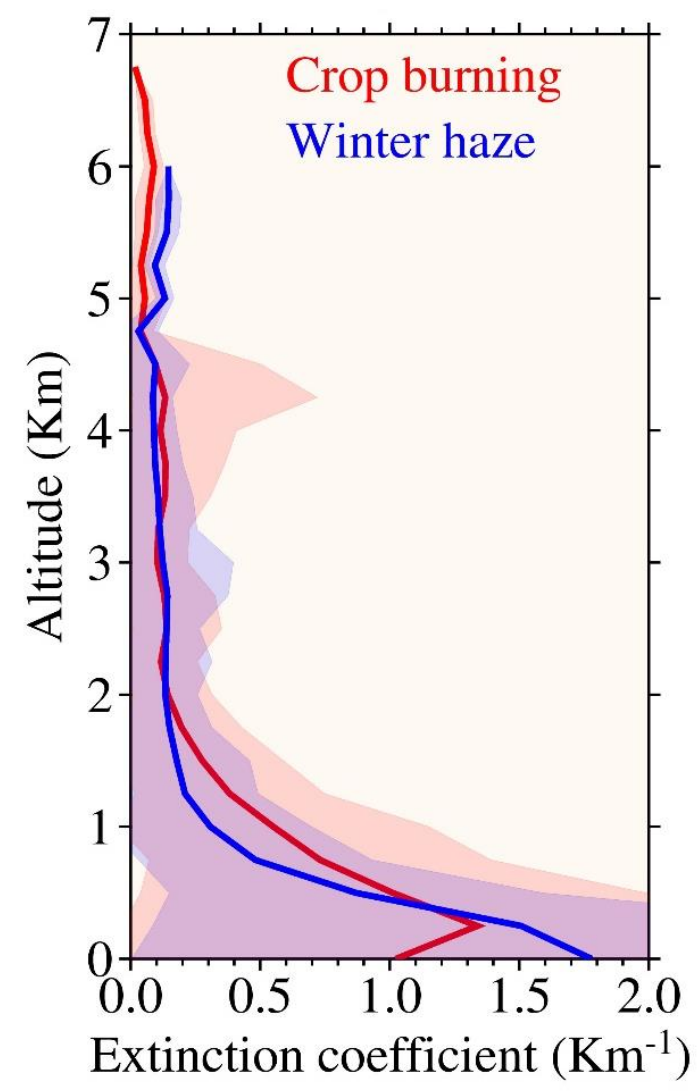

Fig. S9. Vertical distribution of aerosols over northern India. The mean vertical distribution of spaceborne lidar measurements from CALIOP derived aerosol extinction coefficients over northern India during crop burning and winter haze periods for the period of 2015-2017. The aerosol extinction coefficient $\left(\mathrm{km}^{-1}\right)$ is shown as a function of altitude. The vast majority of aerosol extinction is located in the lowest $\sim 1 \mathrm{~km}$ tropospheric layer above ground.

802

803

804 

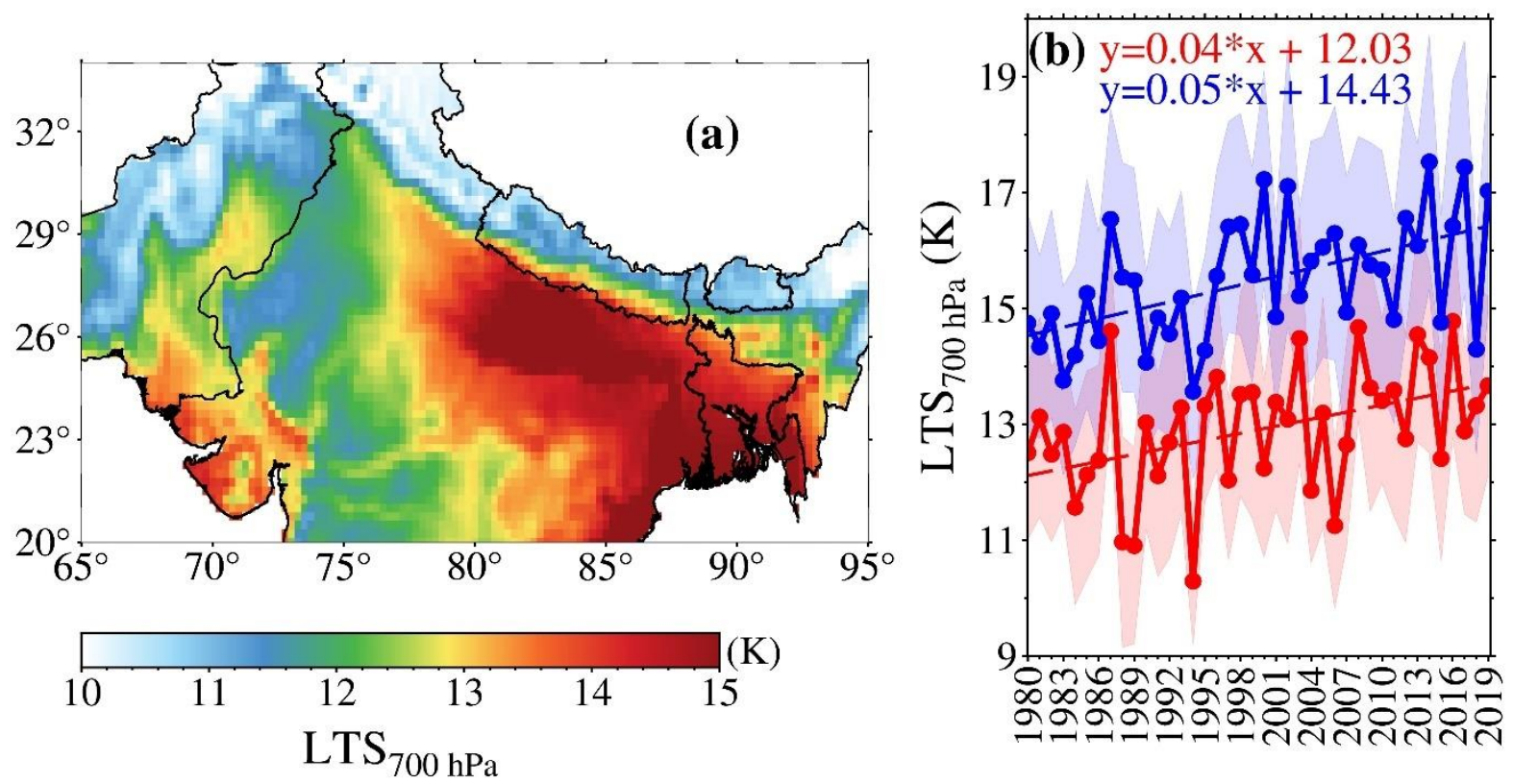

805

806

807

808

809

810

811

812

813

814

815

816

817

818

819

820

821

822

823

Fig. S10. Climatology and trends in lower tropospheric stability. Lower tropospheric stability (LTS) climatology and trends. The LTS calculated for $700 \mathrm{hPa}$ relative to ground surface (shown for $850 \mathrm{hPa}$ in Fig. 3) is shown as (a) the multidecadal average for the 3-month smog period (November - January) from 1980-2019, with enhanced LTS along northern India. (b) Long-term positive trends in LTS averaged over the IGP shown separately for crop burning (November mean in red) and winter haze (December-January mean in blue) periods. Shading represents \pm 1 standard deviation. 

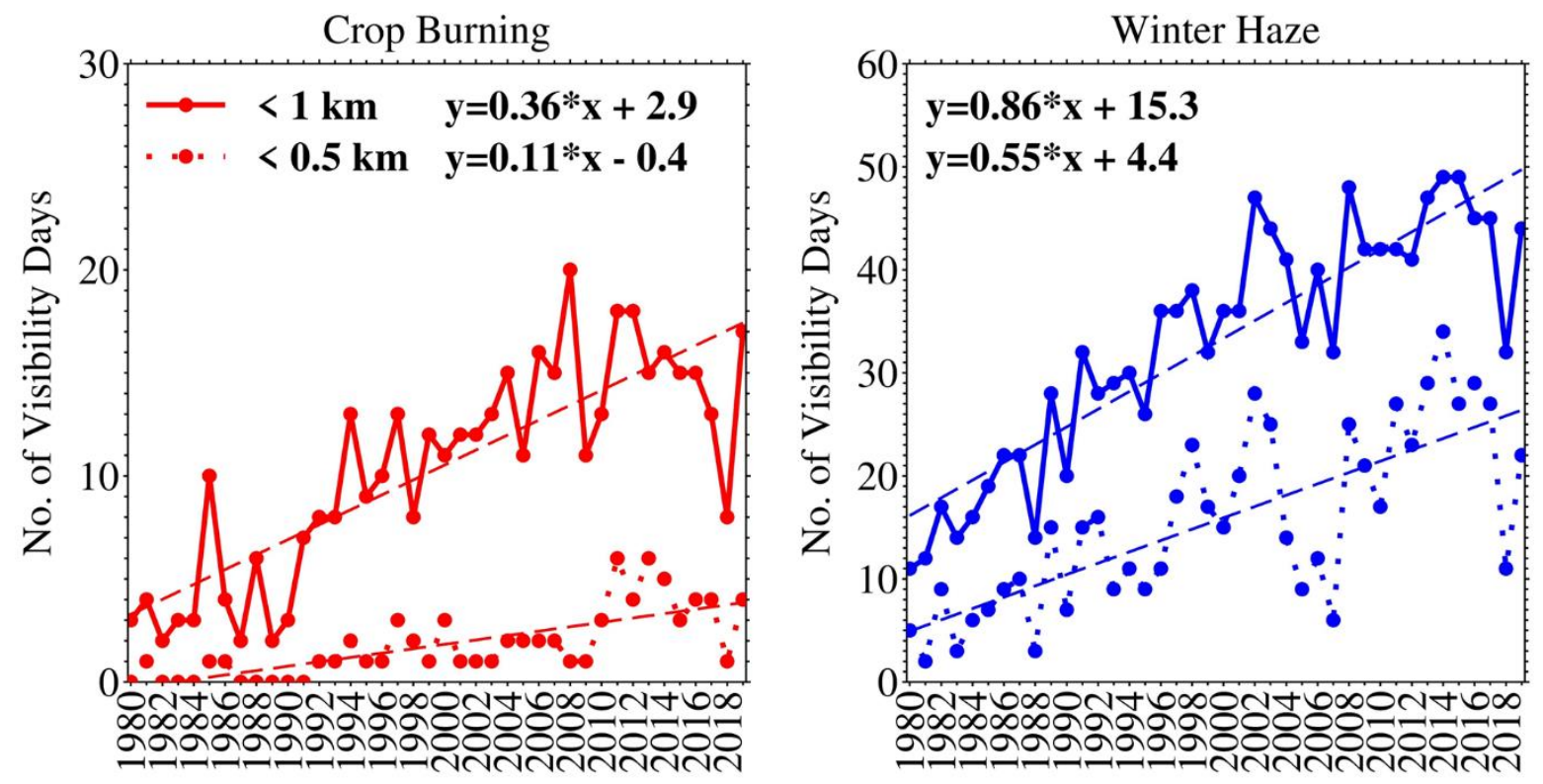

Fig. S11. Visibility degradation in northern India in the last four decades. Trends in the number of low visibility days from 1980 to 2019 averaged over northern India for (left) crop burning period in November (out of 30 days) and (right) winter haze period in December-January (out of 62 days). Days with visibility $<1 \mathrm{~km}$ is shown in bold time series whereas $<0.5 \mathrm{~km}$ in dotted. Linear trend lines are shown as dashed lines; with the corresponding regression equations indicated in the legend. 


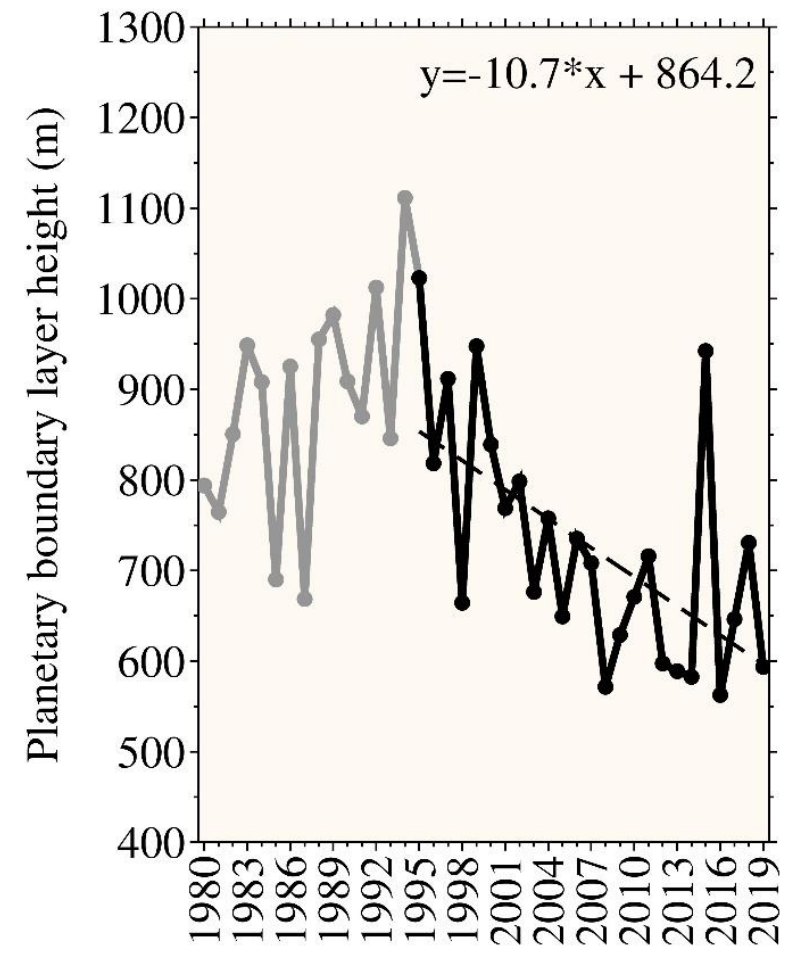

Fig. S12. Decline in planetary boundary layer over northern India. Time series and trend of the monthly-mean planetary boundary layer (PBL) height (in meters) averaged over the IGP obtained from MERRA-2 reanalysis data. The PBL heights were averaged for the three-month period from November to January. The PBL height over the IGP follows a declining trend since the mid-1990s i.e. (shown in black), after an initial uptrend during the 1980s (shown in grey). The decreasing trend from 1995 to 2019 is $-10.7 \pm 2.9 \mathrm{~m} \mathrm{yr}^{-1}$, leading to a $30 \%$ reduction in PBL height during the 25-yr period. Linear trend line is shown as a dashed line; with the corresponding regression equation indicated in the legend. 
868

869

870

871

872

873

874

875

876

877

878

879

880

881

882

883

884

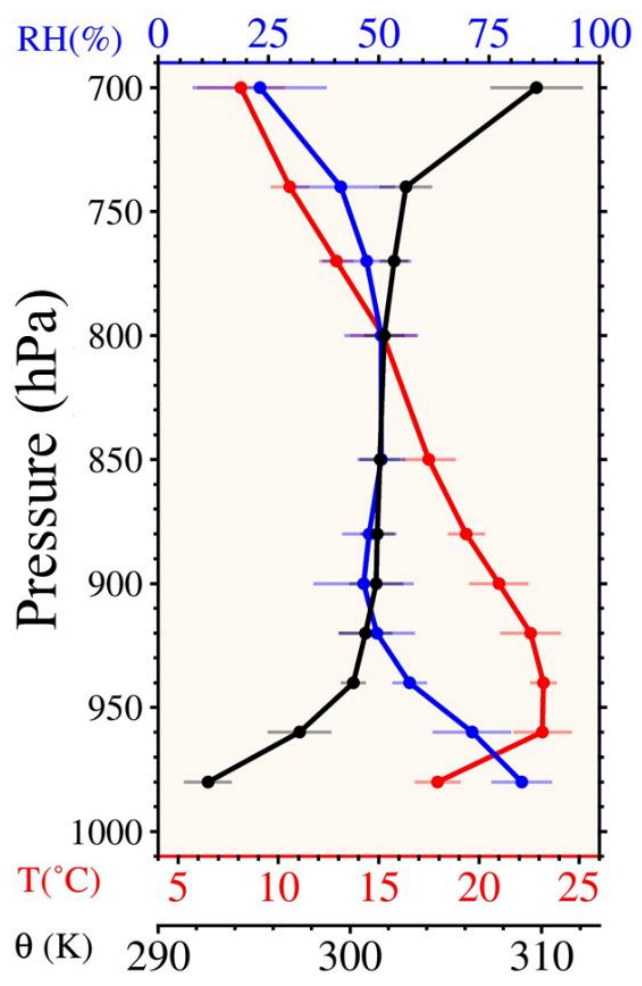

Fig. S13. Vertical distribution of air temperature (red), potential temperature ( $\theta$ in black) and relative humidity (upper axis in blue), averaged from 31 October to 6 November 2017 (5:30am local-time), indicating pronounced temperature inversion and high relative humidity in the lowest tropospheric layers associated with smog occurrence. 
885

886

887

888

889

890

891

892

893

894

895

896

897

898

899

900

901

902

903

904

905

906

907

\section{SI References}

1. A.M. Sayer, N.C. Hsu, C. Bettenhausen, M.K. Jeong, G. Meister, Effect of MODIS terra radiometric calibration improvements on Collection 6 Deep blue aerosol products: Validation and terra/aqua consistency. J. Geophys. Res. 120, 12,157-12,174 (2015). doi:10.1002/2015JD023878.

2. N.G. Loeb, N. Manalo-Smith, W. Su, M. Shankar, S. Thomas, CERES top-of-atmosphere earth radiation budget climate data record: Accounting for in-orbit changes in instrument calibration. Remote Sens. 8, 182 (2016). https://doi.org/10.3390/rs8030182.

3. W. Su, J. Corbett, Z. Eitzen, L. Liang, Next-generation angular distribution models for topof-atmosphere radiative flux calculation from CERES instruments: Validation. Atmos. Meas. Tech. 8, 3297-3313 (2015). https://doi.org/10.5194/amt-8-3297-2015.

4. D.P. Kratz, S.K. Gupta, A.C. Wilber, V.E. Sothcott, Validation of the CERES Edition-4A Surface-Only Flux Algorithms. J. Appl. Meteor. Clim. 59, 281-295 (2020).

5. H. Hersbach et al., The ERA5 global reanalysis. Q. J. R. Meteorol Soc. 146, 1999-2049 (2020).

6. I. Durre, R.S. Vose, D.B. Wuertz, Overview of the integrated global radiosonde archive. $J$. Clim. 19, 53-68 (2006).

7. I. Durre, X. Yin, Enhanced radiosonde data for studies of vertical structure. Bull. Am. Meteor. Soc. 89, 1257-1262 (2008). 